Pacific Northwest

National Laboratory

Operated by Battelle for the

U.S. Department of Energy

\title{
FY06 Annual Report: Amorphous Semiconductors for Gamma Radiation Detection (ASGRAD)
}

\author{
BR Johnson \\ C Henager \\ BJ Riley \\ Y Zhang \\ JV Crum \\ V. Shutthanandan \\ SK Sundaram
}

January 2007

Prepared for the U.S. Department of Energy

under Contract DE-AC05-76RL01830 


\title{
FY06 Annual Report: Amorphous Semiconductors for Gamma Radiation Detection (ASGRAD)
}

\author{
B. R. Johnson \\ B. J. Riley \\ J. V. Crum \\ S. K. Sundaram \\ C. Henager \\ Y. Zhang \\ V. Shutthanandan
}

January 2007

Work performed for the Office of Defense Nuclear Nonproliferation (NA-20) Office of Nonproliferation Research and Development (NA-22) under Project Number PL06-136-PD05

Prepared for the U.S. Department of Energy under Contract DE-AC05-76RL01830

Pacific Northwest National Laboratory

Richland, Washington 99354 


\section{Summary}

We describe progress in the development of new materials for portable, room-temperature, gammaradiation detection at Pacific Northwest National Laboratory. High Z, high resistivity, amorphous semiconductors are being designed for use as solid-state detectors at near ambient temperatures; their principles of operation are analogous to single-crystal semiconducting detectors. Compared to single crystals, amorphous semiconductors have the advantages of rapid, cost-effective, bulk-fabrication, nearnet-shape fabrication of complicated geometries, compositional flexibility, and greater electronic property control. The main disadvantage is reduced-charge carrier mobility. The focus of this project is to develop optimized amorphous semiconductor materials for gamma detection applications that leverage their material advantages while migitating their limitations.

During the first year of this project, several important milestones were accomplished. Environmental safety and health issue were addressed, and procedures were developed and approved for processing, cutting, polishing and characterizing these materials at several different locations in PNNL. The main focus was on process development, and significant progress was made. Several technical processing challenges were encountered and overcome, and we have developed techniques to successfully synthesize amorphous, crack-free ingots of $\mathrm{CdGe}_{\mathrm{X}} \mathrm{As}_{2}$ glass $1.0 \mathrm{~cm}$ in diameter and $\sim 4 \mathrm{~cm}$ long with $\mathrm{Ge}$ content from $\mathrm{X}=0.45$ to $\mathrm{X}=0.85$ - demonstrating compositional flexibility unattainable in single crystal $\mathrm{CdGeAs}_{2}$. Further development is planned to extend the compositional range even farther. Additionally, a collaborative working relationship was developed with Prof. Angus Rockett at the University of Illinois at Urbana-Champaign (UIUC). This has been a fruitful and interactive relationship. Specimens are being analyzed at UIUC, and processing refinements to improve properties are being made based on their feedback. Based on the lessons learned and progress to date, the strategy for future work has been refined, and is described in a separate section. 



\section{Abbreviations and Acronyms}

\begin{tabular}{ll} 
BSE & Back-scattered electron \\
CVD & Chemical vapor deposition \\
DSC & Differential scanning calorimeter \\
DTA & Differential thermal analysis \\
EDS & Energy dispersive spectroscopy \\
EMSL & Environmental Molecular Sciences Laboratory \\
FTIR & Fourier transform infrared \\
IBA & Ion beam analysis \\
IR & Infrared \\
IV & Current - voltage \\
NIST & National Institute for Standards and Technology \\
NOMSL & Non-oxide Materials Synthesis Laboratory \\
PIXE & Particle-induced X-ray emission \\
PNNL & Pacific Northwest National Laboratory \\
RBS & Rutherford backscattering \\
SEM & Scanning electron microscopy \\
SOW & Statement of work \\
STA & Simultaneous thermal analysis \\
TGA & Thermogravimetric analysis \\
UHV & Ultra-high vacuum \\
UIUC & Ultraviolet visible near infrared \\
UV-VIS-NIR & Atraction \\
Z & Sity of Illinois at Urbana-Champaign \\
\hline
\end{tabular}





\section{Contents}

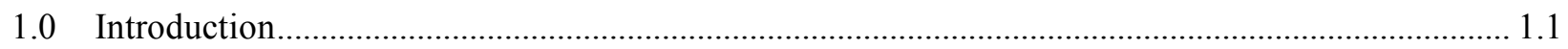

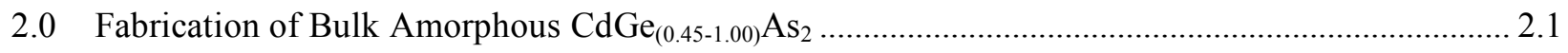

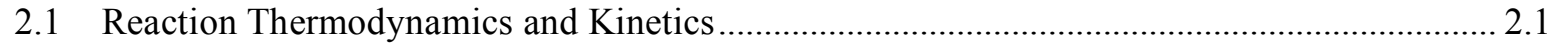

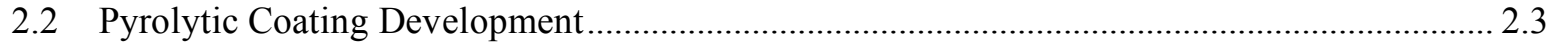

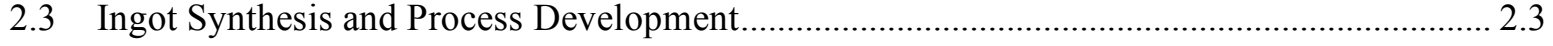

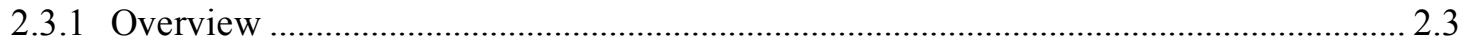

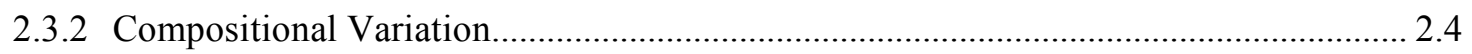

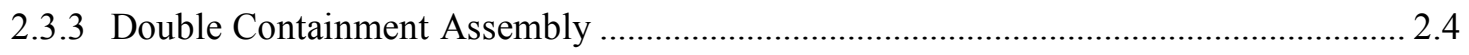

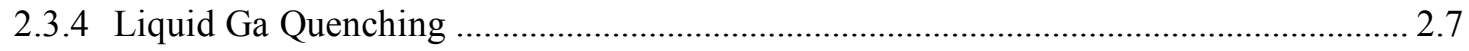

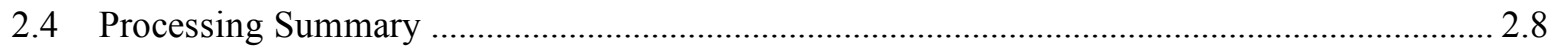

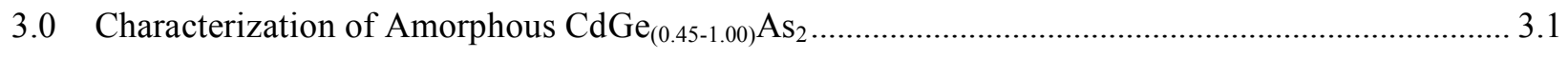

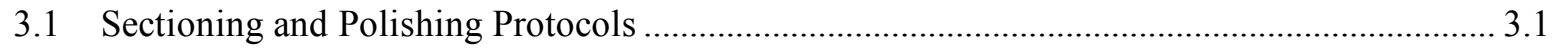

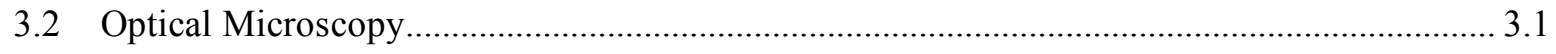

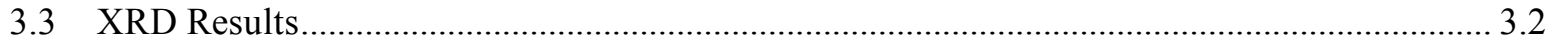

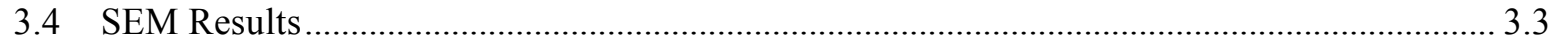

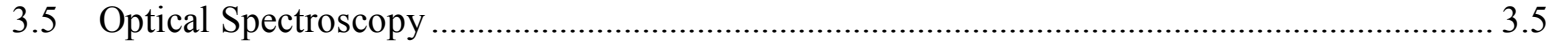

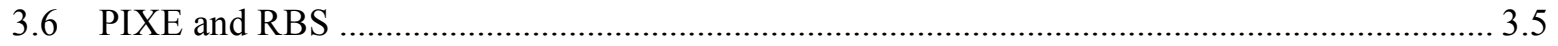

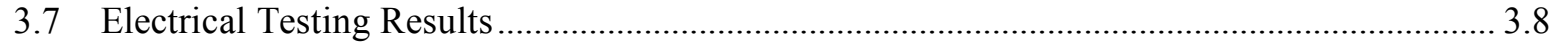

4.0 Collaboration With the University of Illinois at Urbana-Champaign (UIUC) ............................. 4.1

4.1 Hall Effect Measurements ...................................................................................................... 4.1

4.2 Current-Voltage Data........................................................................................................... 4.2

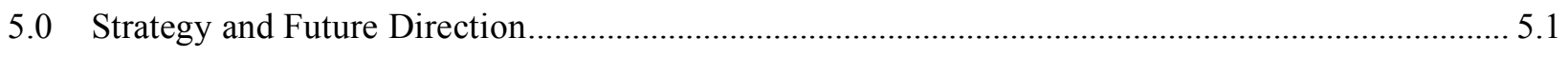

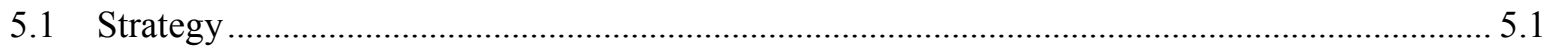

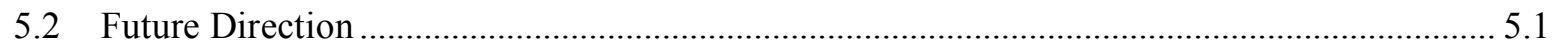

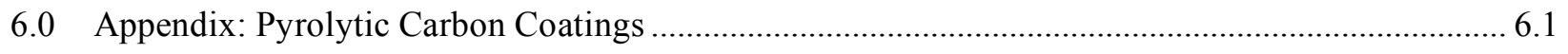

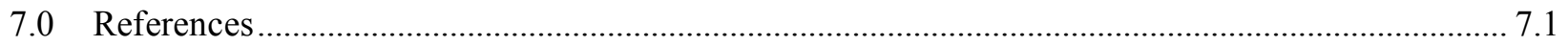




\section{Figures}

Figure 2.1. Simultaneous (DTA \& TGA) thermal analysis experiment done with elemental Cd, Ge, and

As.

Figure 2.2. Aluminum DSC sample pans after thermal experiment with elemental $\mathrm{Cd}$, Ge, and As. ...... 2.2

Figure 2.3. Sequential heating tests done with elemental $\mathrm{Cd}, \mathrm{Ge}$, and As in evacuated, sealed, fused quartz ampoules.

Figure 2.4. M-Braun nitrogen-purged glovebox for anoxic elemental processing conditions.

Figure 2.5. Picture of unreacted $\mathrm{Ge}$, As, and $\mathrm{Cd}$ (respectively from the left side) for ASGRAD-23 in an evacuated and sealed quartz tube-ruler is in centimeters.

Figure 2.6. Top: rocking furnace and secondary containment (time-lapse used show full range of motion); Bottom: picture of an ingot $\mathrm{CdGe}_{0.65} \mathrm{As}_{2}$.

Figure 2.7. Glass formation tendency in $\mathrm{CdGe}_{\mathrm{x}} \mathrm{As}_{2}$ as $x$ is varied from $0.0-1.2$ as defined by Hruby

Figure 2.8. Top: double containment schematic; Bottom: double containment ampoule with copper..... 2.6

Figure 2.9. Thermal conductivity of different metals (Lide 2007). 2.7

Figure 2.10. Liquid gallium in an alumina crucible at $\sim 150^{\circ} \mathrm{C}$. 2.8

Figure 3.1. Reflected, cross-polarized optical micrographs of six cross-sectioned specimens of

$\mathrm{CdGe}_{\mathrm{X}} \mathrm{As}_{2}$ processed using different conditions.

Figure 3.2. XRD results for $\mathrm{CdGe}_{\mathrm{x}} \mathrm{As}_{2}$ compositional variation.

Figure 3.3. SEM BSE micrograph (A) and accompanying EDS elemental dot maps $(\mathrm{B}$ to $\mathrm{H})$ for ASGRAD-10, a water-quenched specimen with a composition of $\mathrm{CdGe}_{1.0} \mathrm{As}_{2}$. The contrast in (A) is due to differences in average atomic number. The intensity of the colors in $\mathrm{B}$ to $\mathrm{E}$ is qualitatively proportional to concentration; the images in $\mathrm{F}$ to $\mathrm{H}$ are composite images.

Figure 3.4. FTIR spectroscopy performed on two different compositions............................................... 3.5

Figure 3.5. Schematic drawing of ion-solid interaction. ......................................................................... 3.5

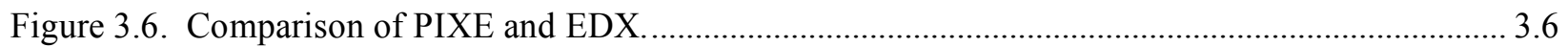

Figure 3.7. PIXE Results for ASGRAD-23 (amorphous $\mathrm{CdGe}_{0.45} \mathrm{As}_{2}$ ), (A), and ASGRAD-30

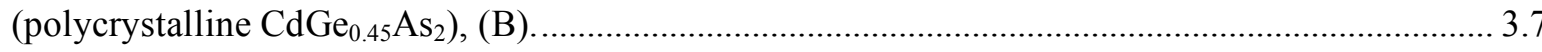

Figure 3.8. RBS Results for ASGRAD-23 (amorphous $\mathrm{CdGe}_{0.45} \mathrm{As}_{2}$ ), (A), and ASGRAD-30 (polycrystalline $\mathrm{CdGe}_{0.45} \mathrm{As}_{2}$ ), (B)......

Figure 4.1. Photographs of the Hall mobility testing apparatus at UIUC. magnet (L) and ASGRAD sample in holder $(\mathrm{R})$.

Figure 4.2. Current-Voltage curves measured by UIUC for a polycrystalline sample (A) ASGRAD-5 and

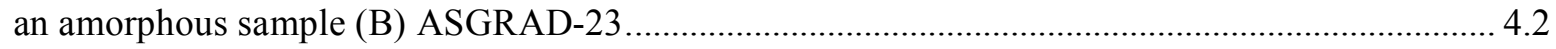

Figure 4.3. Resistivity as a function of temperature for amorphous specimen ASGRAD-23.................. 4.3 
Figure 6.1. Top: CVD apparatus for applying graphite coating to quartz tubes; Bottom: evacuated and sealed quartz tube with graphite coating on interior.

\section{Tables}

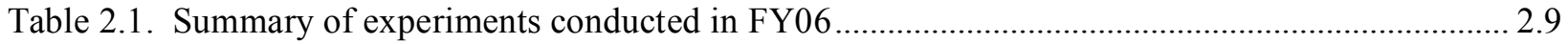

Table 3.1. Summary of compositional analysis from IBA experiments ................................................... 3.7 


\subsection{Introduction}

We proposed to design and develop new materials for portable, near-ambient temperature, gammaradiation detection. The two principal techniques used to detect and obtain energy resolution information from gamma radiation are based on either scintillators or semiconductors. Scintillation detectors are designed so that incident gamma photons interact with the active material to generate optical photons that can be detected and amplified by photo-multiplier tubes. Semiconductor detectors are designed to directly collect the electrons that incident gamma photons create as they interact with the active material. There are three processes by which gamma photons generate electrons in the active material: the photo electric effect, Compton Scattering, and pair production. The production of electrons by each of these processes is a probability function dependant upon the energy of the incident gamma photon and the atomic number and the density of that material. Consequently, dense, high $\mathrm{Z}$ materials yield a larger number of gamma-produced electrons than low $\mathrm{Z}$, low density materials. The focus of this project is to design and develop materials for semiconductor-based gamma radiation detection.

A single $1 \mathrm{MeV}$ gamma photon has the possibility of producing a small pulse on the order of tens to hundreds of nA's within 100ns. A bulk sample with approximately $1 \mathrm{~cm}^{3}$ volume is needed in order to collect all of the energy from the multiple scattering events that the incident gamma will undergo as it interacts with the active material. With such a small signal, sources of electrical noise create significant problems and interfere with signal detection. Semiconductor materials are characterized by an energy gap between their valence and conduction bands. For those materials with small band gaps (e.g. $\leq 1 \mathrm{eV})$ it is possible to promote electrons from the valence to the conduction band with just thermal energy. Consequently, small band-gap materials such as single crystal $\mathrm{Si}$ and Ge cannot be used as gamma radiation detectors at room temperature because of thermal noise. They require cryogenic cooling to operate as a gamma detector. Thus, a room temperature gamma radiation material would require a semiconductor with a band gap larger than $1 \mathrm{eV}$.

Electrical charges created by incident gamma photons are collected in semiconductor detectors by creating electrodes on opposite sides of the material and applying a large electric field across it (10 - 1000 $\mathrm{V} / \mathrm{cm}$ ). The large electric field accelerates the gamma-generated charges to the electrodes and allows rapid pulse detection and improves energy resolution. Thus another potential source of electrical noise is the leakage of current across the electrodes of the detector material. Consequently, a material with high resistivity (on the order of $10^{9} \mathrm{ohm}-\mathrm{cm}$ ) is required to keep leakage currents less than $1 \mathrm{nA}$ and thus minimize noise.

In summary, a material that meets the design goals for room-temperature, semiconductor-based, gamma radiation detection would be a high $\mathrm{Z}$, moderate band-gap, high-resistivity semiconductor. These criteria can only be satisfied by multi-component semiconductors. An example of this is single crystal CdZnTe, which has been under serious development for many years, and has been successfully applied in a large number of applications.

Single crystals are generally preferred for most semiconductor applications, because they have a wellordered electronic structure that facilitates rapid charge carrier transport. However, there are significant processing problems associated with the growth of large $\left(\sim 1 \mathrm{~cm}^{3}\right)$, defect-free, single crystals from multi- 
component materials. These challenges still require a significant amount of research and development to provide solid results and answers.

In light of this need, we have proposed the development of amorphous semiconductors as a potential alternative solution for room-temperature gamma radiation detection. Compared to single crystals, amorphous semiconductors have the potential advantages of rapid, cost-effective, bulk-fabrication; nearnet-shape fabrication of complicated geometries; compositional flexibility, and greater compositional and electronic property control. The main disadvantage of an amorphous semiconductor is reduced-charge carrier mobility due to the disordered structure. In this project, we are focusing our efforts to mitigate the technical problems with amorphous semiconductors to develop an optimized material for gamma detection.

The materials selected for this study were based on the criterion stated above: semiconducting, moderateto-high atomic number, moderate band-gap, high-resistivity, and glass forming. Traditional semiconductor materials are found between groups I through VI on the periodic table. A minimum Z value of 29 was arbitrarily chosen with the objective to maximize the probability of gamma interaction. These boundary conditions specified a small section of the periodic table consisting of 18 elements. Some of the better-known multi-component semiconductors within this area of the periodic table are the chalcopyrite family, consisting of $\mathrm{A}^{\mathrm{I}} \mathrm{B}^{\mathrm{IV}} \mathrm{C}^{\mathrm{V} 2}$ and $\mathrm{A}^{\mathrm{I}} \mathrm{B}^{\mathrm{III}} \mathrm{C}^{\mathrm{V} / 2}$ compounds. And, within this family of semiconductors, $\mathrm{CdGeAs}_{2}$ is the best-known glass-former. Single crystal CdGeAs 2 has very excellent charge carrier mobility ( $\sim 10^{4} \mathrm{~cm}^{2} /(\mathrm{Vs})$ at room temperature) (Rud et al. 2000b; Rud et al. 2000a)), and has one of the highest reported non-linear optical coefficients. It is also iso-structural with another multicomponent single crystal chalcopyrite semiconductor, $\mathrm{AgGaSe}_{2}$, which has demonstrated radiation detection capability (Roy et al. 2004). In the amorphous form, $\mathrm{CdGeAs}_{2}$ has a large reported compositional range $(\mathrm{Ge}=0.2-1.3)$ and also has reported substitutional ability (e.g. replace Ge with other elements such as Si or Sb) (Risbud 1996; Hruby and Stourac 1969). These properties make it a very good candidate for investigating the potential application of amorphous semiconductors for radiation detection applications. Unfortunately, its band gap $(\sim 0.9-1.0 \mathrm{eV})$ and its resistivity $\left(10^{7}-10^{9} \mathrm{Ohm}-\mathrm{cm}\right)$ are somewhat lower than optimal. However, because it is a known multi-component, glass-forming semiconductor, it lies within the targeted region of the periodic table, and it has very large compositional flexibility, it is a good material to demonstrate compositional control of gamma radiation detection properties. Additionally, the fact that it is iso-structural with other higher $\mathrm{Z}$ chalcopyrites such as $\mathrm{AgGaSe}_{2}$ may allow us to blend these compounds together in an amorphous state to create an ideal amorphous gamma radiation detection material. Our intent is to initiate our study of gamma radiation detection in amorphous semiconductors with $\mathrm{CdGeAs}_{2}$, and then make compositional modifications to it to demonstrate compositional control of radiation detection properties, with the goal of optimizing the materials performance. 


\subsection{Fabrication of Bulk Amorphous $\mathrm{CdGe}_{(0.45-1.00)} \mathrm{As}_{2}$}

The starting point for this project was synthesis of bulk amorphous $\mathrm{CdGe}_{(0.45-1.00)} \mathrm{As}_{2}$,. This required an understanding of the reaction thermodynamics and kinetics. Issues such as developing protective pyrolytic coatings and processing details regarding ingot fabrication will be discussed.

\subsection{Reaction Thermodynamics and Kinetics}

The chemical reactions involved in forming $\mathrm{CdGeAs}_{2}$ were studied with differential scanning calorimetry (DSC), differential thermal analysis (DTA), and thermogravimetric analysis (TGA) experiments with stoichiometric quantities of the raw elements. These experiments were done to look for the existence of any highly exothermic reactions or the occurrence of sudden mass losses, either of which might create safety concerns for bulk synthesis. The results were used to determine a suitable heating protocol for processing these materials in sealed, evacuated, fused quartz ampoules. Stoichiometric quantities of Cd, $\mathrm{Ge}$, and As were loaded into aluminum DSC crucibles with the total mass being on the order of $\sim 15 \mathrm{mg}$. The crucibles were hermetically sealed to minimize volatilization losses. Experiments were run in both a Perkin-Elmer ${ }^{\circledR}$ DSC and a TA Instruments ${ }^{\circledR}$ simultaneous thermal analyzer (STA). Three main thermodynamic events were observed (Figure 2.1): $325^{\circ} \mathrm{C}$ (melting of $\mathrm{Cd}$ ), $573^{\circ} \mathrm{C}$ (melting of As), and $592^{\circ} \mathrm{C}$ (reaction of $\mathrm{Cd}$ and As). The gradual change in mass was suspected to be due to temperature effects or possible oxidation of the materials (Figure 2.2).

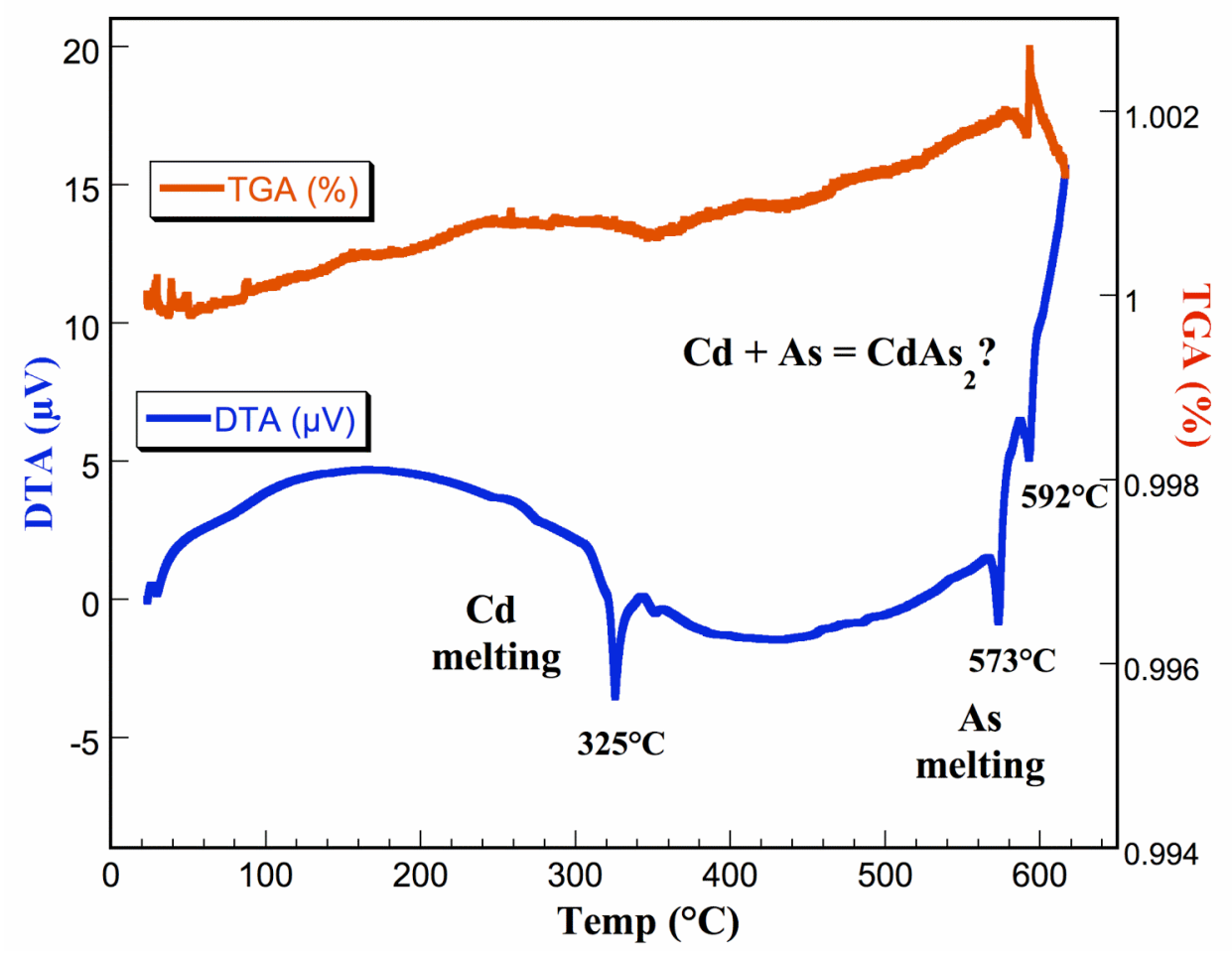

Figure 2.1. Simultaneous (DTA \& TGA) thermal analysis experiment done with elemental $\mathrm{Cd}, \mathrm{Ge}$, and As. 
One of the problems encountered with the thermal analysis experiments was the chemical incompatibility between the materials being tested and the commonly available materials used to make sample holders for DSC experiments. Figure 2.2 is a picture of an Al DSC pan that reacted with the Cd-Ge-As mixture.

Arsenic has a high vapor pressure; thus, it was necessary to use sealed crucibles for the thermal analysis experiments. Hermetically sealed DSC pans are available in $\mathrm{Al}$ and $\mathrm{Au}$. However, Ge alloys with Au at $320^{\circ} \mathrm{C}$, and $\mathrm{Al}$ is only suitable up to $620^{\circ} \mathrm{C}$ (melts at $660^{\circ} \mathrm{C}$ ). Thus, it was not possible to conduct thermal-analysis experiments up to the synthesis temperatures used for this material $\left(\sim 800^{\circ} \mathrm{C}\right)$.

Additionally, it was obvious that the $\mathrm{Al}$ was not compatible with this system because it reacted with the mixture.

In addition to the thermal analysis, trial heating experiments were conducted with small mixtures of the elements in evacuated, sealed, fused quartz ampoules. A typical ampoule is shown in Figure 2.3. The trial specimens were heated up to specific temperatures of interest, as indicated by the preliminary DSC experiments, held at those temperatures for an hour or two, and cooled, to observe what had occurred. The primary concern was to identify the reactions recorded by the DSC experiments and to determine if there were any adverse reactions with the fused quartz.

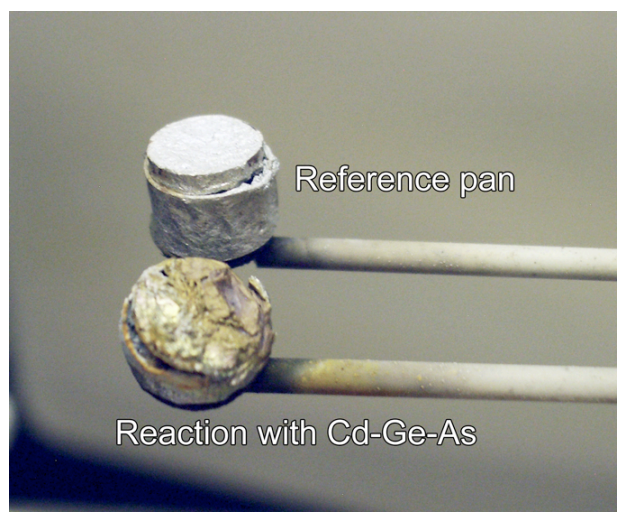

Figure 2.2. Aluminum DSC sample pans after thermal experiment with elemental $\mathrm{Cd}, \mathrm{Ge}$, and As.

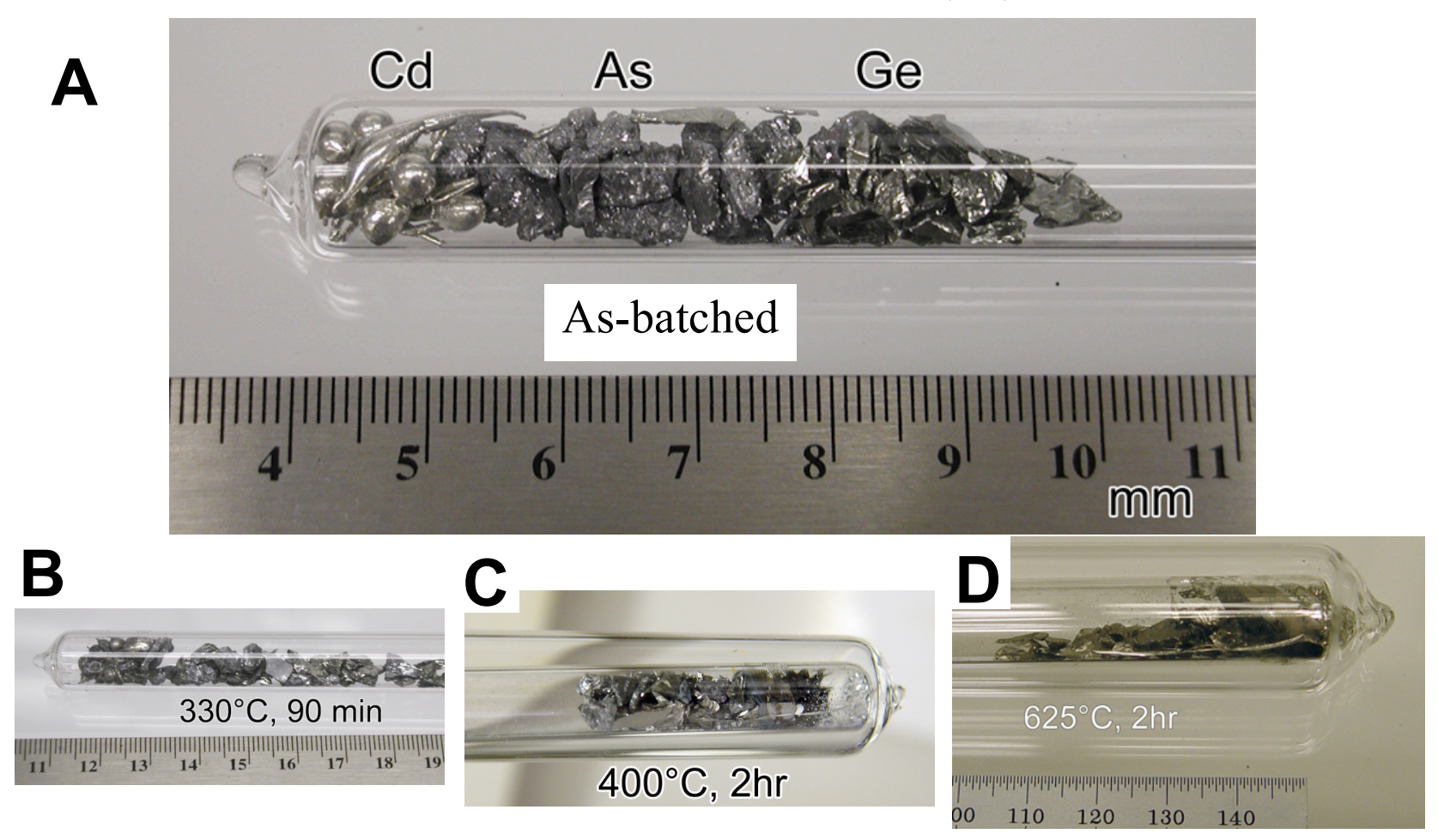

Figure 2.3. Sequential heating tests done with elemental $\mathrm{Cd}, \mathrm{Ge}$, and As in evacuated, sealed, fused quartz ampoules. 
Two main reaction events were observed that influenced the development of our heating profile. The first significant event was the melting of $\mathrm{Cd}$ at $325^{\circ} \mathrm{C}$. A dwell at $400^{\circ} \mathrm{C}$ for $2 \mathrm{hr}$ was chosen to allow $\mathrm{Cd}$ time to melt completely and initially alloy with the other two elements. Lower temperatures did not seem adequate for this purpose (Figure 2.3B). The other significant events were the melting of As at $573^{\circ} \mathrm{C}$ and another peak at $593^{\circ} \mathrm{C}$ (Figure 2.1), which may correspond to a reaction between $\mathrm{Cd}$ and As. Since the reported melt temperature for $\mathrm{CdAs}_{2}$ is $621^{\circ} \mathrm{C}$, and since this compound is the glass-forming backbone for $\mathrm{CdGeAs}_{2}$, a dwell at $650^{\circ} \mathrm{C}$ for $2 \mathrm{hr}$ was chosen to facilitate its formation. The last heating segment takes the melt up to $800^{\circ}$ where rocking of the sample ampoule begins, and the melt is homogenized. The finalized heating profile is shown below:

$$
\begin{aligned}
&{ }^{(1)} \mathbf{R} @ 3^{\circ} \mathrm{C} / \min 400^{\circ} \mathrm{C} \rightarrow{ }^{(2)} \mathbf{D} 2 \mathrm{hrs} \rightarrow{ }^{(3)} \mathbf{R} @ 3^{\circ} \mathrm{C} / \min 650^{\circ} \mathrm{C} \rightarrow{ }^{(4)} \mathbf{D} 2 \mathrm{hrs} \rightarrow{ }^{(5)} \mathbf{R} @ 3^{\circ} \mathrm{C} / \mathrm{min} 800^{\circ} \mathrm{C} \rightarrow \\
&{ }^{(7)} \mathbf{D} @ 10^{\circ} \mathrm{C} / \min 650^{\circ} \mathrm{C} \rightarrow{ }^{(8)} \mathrm{D} 0.5 \mathrm{hrs} \rightarrow \text { quench }
\end{aligned}
$$

\subsection{Pyrolytic Coating Development}

Pyrolytic carbon coatings were applied to the interior of the ampoules during the early stages of the project. This is a common processing technique often used in the synthesis of non-oxide materials using evacuated fused silica tubing. This processing step was eventually deemed unnecessary, and was eliminated. Further discussion of the development and implementation of pyrolytic carbon coatings is provided in the Appendix.

\subsection{Ingot Synthesis and Process Development}

\subsubsection{Overview}

Oxygen and water tend to be the most significant sources of contamination for non-oxide materials. Successful processing of these materials is contingent upon minimizing these contaminants. The NonOxide Materials Synthesis Laboratory (NOMSL) is a processing laboratory at PNNL uniquely designed for handling and processing these materials under anhydrous and anoxic conditions. One of the central pieces of equipment is a nitrogen-purged glovebox, shown in Figure 2.4. All weighing, batching, and filling of ampoules occurred in this glove box. High-purity chemicals are transferred into the glove box, weighed out in the specified ratios, and loaded into a pre-cleaned quartz tube. The ampoules are cleaned by rinsing them in a solution of ammonia and hydrogen peroxide following by a rinse in $5 \% \mathrm{HF}$ acid, and then calcining them at $1100^{\circ} \mathrm{C}$ to remove adventitious hydrocarbon contamination. They are subsequently transferred into the glove box and heated up to $1160^{\circ} \mathrm{C}$ to anneal them and remove adsorbed moisture. An ultra-high vacuum (UHV) gate valve with a compression fitting attached to one end is then transferred into the glove box.

The ampoule is attached to the compression fitting on the gate valve (valve closed). This process allows the elements in the ampoule to be transferred out of the glove box without exposing them to the atmosphere. This setup is then passed out of the glovebox through the large antechamber where it was connected to the vacuum assembly. Here, the ampoule can be evacuated to high vacuum levels $\left(10^{-8}\right.$ Torr), purged with Matheson research purity $\mathrm{Ar} / \mathrm{H}_{2}$ or Ar several times, and re-evacuated. Once the ion gauge readout reached the desired pressure $\left(\sim 10^{8}\right.$ Torr range), the ampoules are sealed with an oxygenpropane torch. See Figure 2.5 for a picture of the unreacted elements. 
Once sealed, the ampoule was loaded into the secondary containment piping in the rocking furnace shown in Figure 2.6A. The secondary containment is designed to contain the debris (glass, chemicals, etc.) in the event of a ruptured ampoule. It is also designed to release the pressure out the open port on the cold snorkel end, which is baffled to trap debris. The vessel is composed of durable stainless steel to prevent decreased strength caused by thermal processing and/or thermal attack.

Once the sample has been adequately homogenized, it is quenched, annealed, cast into epoxy, cut, polished, and analyzed. An example of a glassy ingot of $\mathrm{CdGe}_{0.65} \mathrm{As}_{2}$ is seen in Figure 2.6B.

\subsubsection{Compositional Variation}

One report in the literature (Sharma et al. 1989) indicated that it was possible to airquench $\mathrm{CdGeAs}_{2}$ into an amorphous state. However, we did not find this to be possible with our experimental process. Initial experiments with water-quenching ampoules also did not yield amorphous ingots. Because of the difficulties experienced in obtaining a single ingot of amorphous, crack-free $\mathrm{CdGeAs}_{2}$, we referred to a paper published by Hong et al. (Hong et al. 1990) where they described the effect on glass formability of compositionally varying the Ge content in Cd-Ge-As. Their thermal analysis results showed that glass formability in Cd-Ge-As could be enhanced by decreasing the Ge content. Figure 2.7 shows data on glass formability as a function of Ge content. The dashed line is an extrapolation of the predicted data, and it was proposed that a $\mathrm{CdGe}_{x} \mathrm{As}_{2}$ material with $x \approx 0.45$ might possess a higher glass formation tendency than $x=0.3$ or $x=0.6$, as published by Hong et al. (1990). Three other compositions were chosen $(x=$ $0.65,0.85$, and 1.0 ) to study the effect of Ge content on other properties also.

\subsubsection{Double Containment Assembly}

Success was obtained in synthesizing amorphous ingots of Cd-Ge-As glass by reducing the Ge content and quenching the ampoules in water. However, due to the rapid cooling rates, the ingots cracked during the quench process. Additionally, it was observed that the molten Cd-Ge-As tended to adhere to the inner walls of ampoules that were carbon coated. Thus, the volume of material quenched into a solid, cylindrical, ingot was reduced because of the layer of Cd-Ge-As that stuck to the carbon-coated ampoule walls. Because of these problems, an alternate processing approach was investigated. The goal was to moderate the cooling rate slightly so as not to thermally shock the ingot and also to eliminate the problem of the melt sticking to the sides of the ampoule. 
A double-ampoule containment approach was designed to meet these goals. The design incorporated the use of two concentric, evacuated, sealed ampoules, one inside of the other. The inner ampoule containing the elements was not coated with carbon. This was done to eliminate the problem of the melt sticking to the carbon coating. The elimination of a carbon coating raised concerns that molten elemental $\mathrm{Cd}$ might attach to the fused quartz walls of the ampoule and result in ampoule failures. An outer ampoule provided the benefit of an additional protective barrier in case the inner ampoule failed. Although two concentric ampoules would be effective in addressing containment concerns, the design was inherently insulating and would not facilitate the rapid heat transfer required for quenching. This issue was addressed by partially filling the space between the two ampoules with a material that had high thermal conductivity (see Figure 2.8). Double containment ampoules filled with $\mathrm{Cu}$ shot, $\mathrm{SiC}$ powder, and $\mathrm{Ag}$ powder were all tested and the $\mathrm{Cu}$ shot filled ones were found to perform the

best. Figure 2.9 shows a plot of thermal conductivity vs. temperature for several materials.

The filler material between the two ampoules not only facilitated rapid heat transfer from the molten Cd-Ge-As to the quench bath, but it also increased the thermal mass of the system, thereby mitigating the $\mathrm{Cd}-\mathrm{Ge}-\mathrm{As}$ to the quench bath, but it also increased the thermal mass of the system, thereby mitigatin
quench rate as compared to a single quartz ampoule being quenched in water. This enabled us to synthesize amorphous, crack-free, ingots with Ge content up to $\mathrm{x}=0.85$.

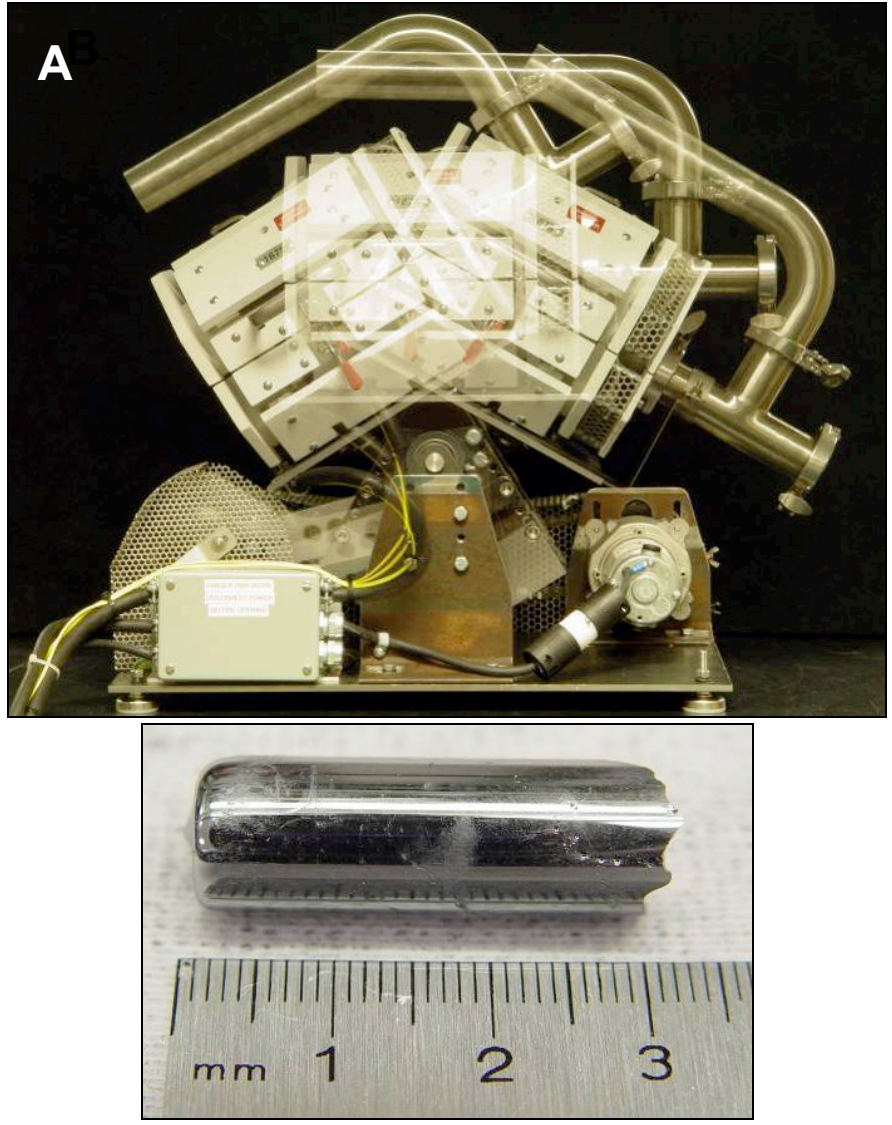

Figure 2.6. Top: rocking furnace and secondary containment (time-lapse used show full range of motion); Bottom: picture of an ingot $\mathrm{CdGe}_{0.65} \mathrm{As}_{2}$. 


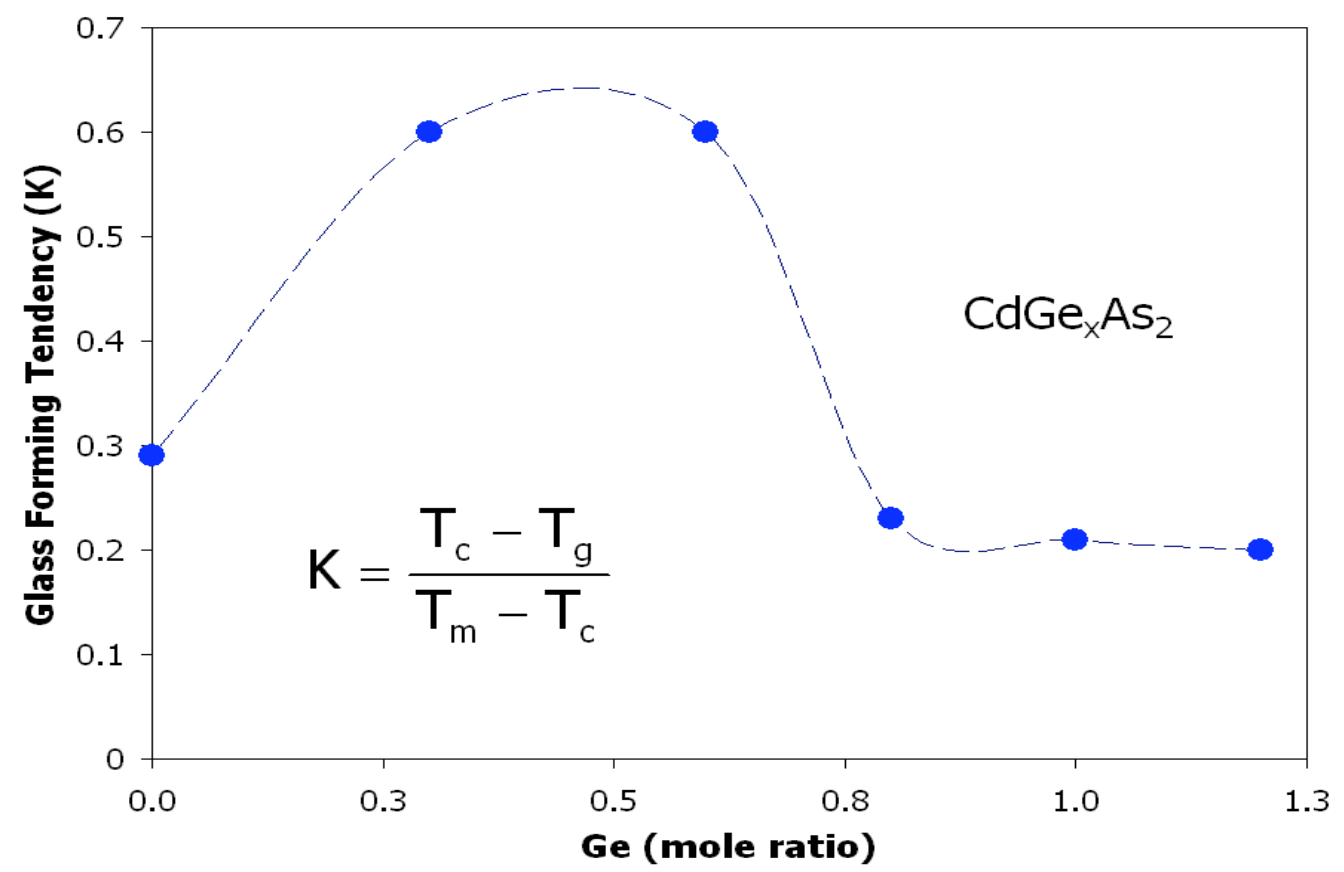

Figure 2.7. Glass formation tendency in $\mathrm{CdGe}_{x} \mathrm{As}_{2}$ as $x$ is varied from $0.0-1.2$ as defined by Hruby (1972).

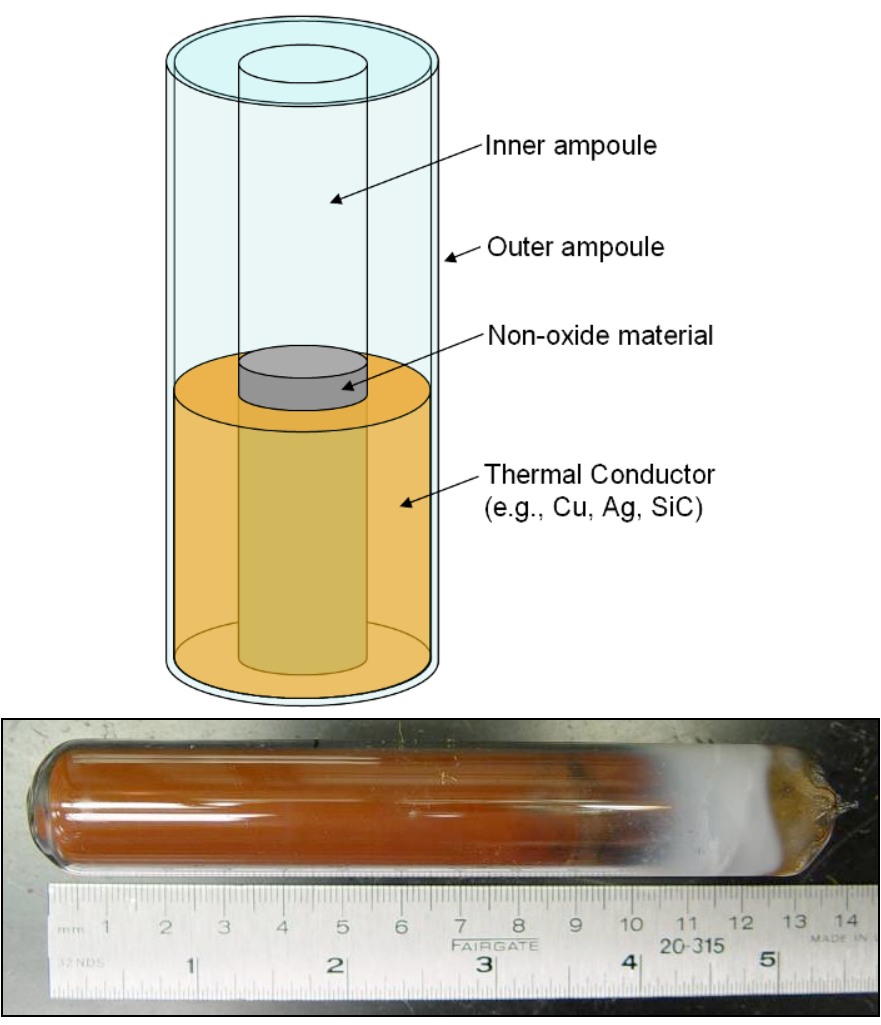

Figure 2.8. Top: double containment schematic; Bottom: double containment ampoule with copper. 


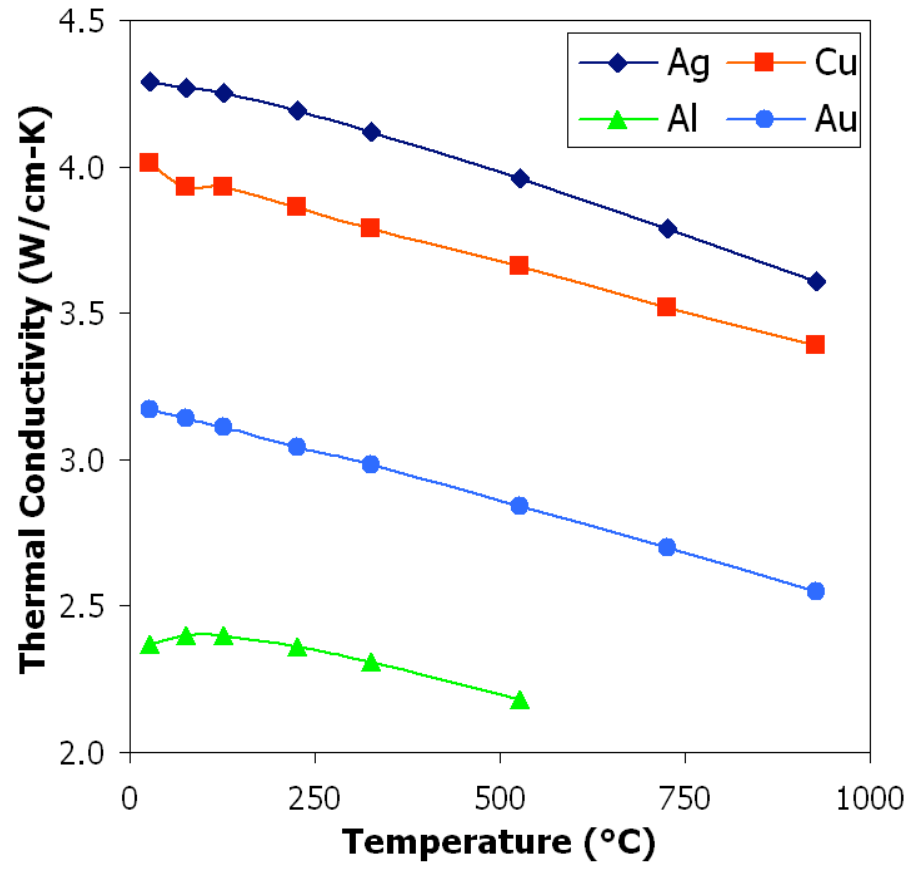

Figure 2.9. Thermal conductivity of different metals (Lide 2007).

\subsubsection{Liquid Ga Quenching}

By the end of the fourth quarter in the fiscal year, we were able to synthesize amorphous, crack-free ingots of Cd-Ge-As glass with a composition of $\mathrm{CdGe}_{0.85} \mathrm{As}_{2}$ and a diameter of $1.0 \mathrm{~cm}$. The processing goal of the project was to synthesize amorphous Cd-Ge-As ingots with a composition of $\mathrm{CdGeAs}_{2}$ and a diameter of $1.0 \mathrm{~cm}$. The processing papers in the open literature regarding the synthesis of amorphous Cd-Ge-As glass indicated that it was possible to synthesize this composition in diameters up to $3 \mathrm{~mm}$, but larger diameter ingots were more challenging (Sharma et al. 1989; Hong et al. 1990; Hruby and Stourac 1969). Thus, though we had advanced the processing capabilities in this field, our main goal was to produce larger, amorphous, crack-free ingots with even higher contents of Ge.

The largest obstacle to this goal was optimizing the quench rate. On the one hand, the quench rate had to be sufficiently fast to prevent crystallization. However, due to the build up of thermal stresses, the quench rate had to be limited to avoid thermally shocking and fracturing the ingot. A rigorous and definitive engineering solution to the problem could have been developed by measuring a variety of material parameters as a function of temperature and composition such as 1) thermal conductivity, 2) yield stress, and 3) coefficient of thermal expansion etc. as well as modeling the heat-transfer rates of the combined ampoule + quench bath $+\mathrm{Cd}-\mathrm{Ge}$-As melt system. Though such an approach would have provided a precise answer to the problem, this solution would exceed the scope and budget of the project, so a more empirical approach was chosen.

Hruby et al. reported the use of molten Ga as a means to quench large (e.g., 1.0-cm diameter) ingots without fracturing the $\mathrm{CdAs}_{2}$ glass (Hruby and Stourac 1969). We chose to test this approach to see if we could obtain similar success with quenching 1.0-cm-diameter amorphous, crack-free ingots of $\mathrm{CdGeAs}_{2}$. 
Figure 2.10 is a picture of the setup. Experiments will be done in FY07 to test the effectiveness of this quench method. The details of the proposed quench process are as follows:

1) Heat and rock the melt at $800^{\circ} \mathrm{C}$ for $24 \mathrm{~h}$.

2) Cool the ampoule inside the furnace at $5^{\circ} \mathrm{C} / \mathrm{min}$ to $\sim 650^{\circ} \mathrm{C}$.

3) Heat the gallium bath to $150^{\circ}$ to $200^{\circ} \mathrm{C}$.

3) Quickly remove the ampoule from the furnace, and quench it in the gallium bath.

4) Allow the ampoule to soak/anneal in the Ga bath for several hours.

5) Remove the ampoule from the Ga bath and anneal it near the glass transition temperature to remove thermal stresses.

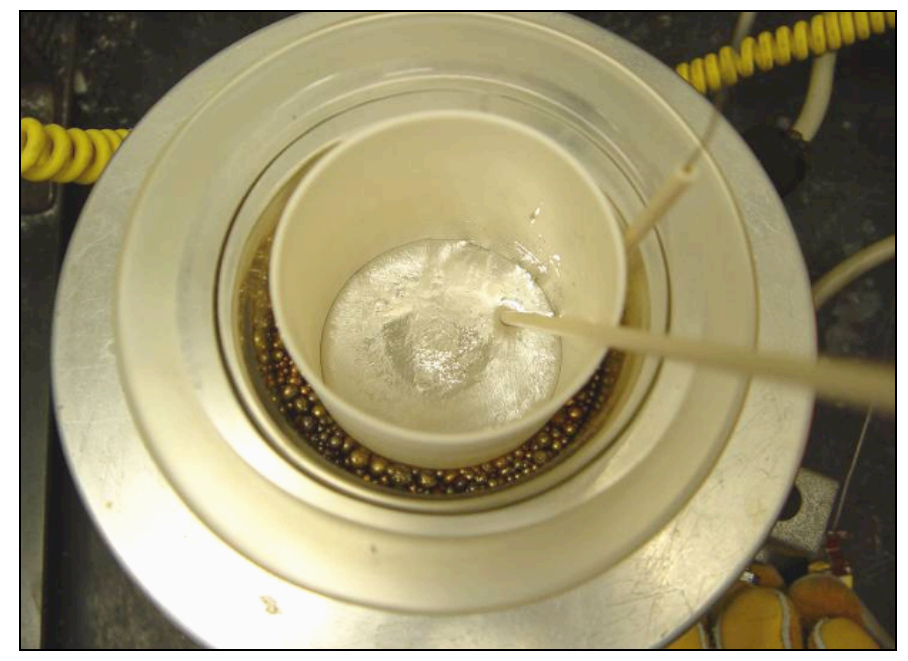

Figure 2.10. Liquid gallium in an alumina crucible at $\sim 150^{\circ} \mathrm{C}$.

\subsection{Processing Summary}

Thirty different experiments were completed during the course of FY06 to synthesize ingots of Cd-Ge-As glass. Table 2.1 shows the various experiments conducted and provides a brief summary for each. 
Table 2.1. Summary of experiments conducted in FY06

\begin{tabular}{|c|c|c|}
\hline ID & Composition & Purpose of Experiment \\
\hline$\# 01$ & $\mathrm{CdGeAs}_{2}$ & First ampoule attempt using powdered Ge \\
\hline$\# 02$ & $\mathrm{CdGeAs}_{2}$ & First ampoule attempt using Ge chunks (special order from Alfa Aesar) \\
\hline$\# 03$ & $\mathrm{CdGeAs}_{2}$ & Double containment ampoule and melt \\
\hline \#04 & $\mathrm{CdGeAs}_{2}$ & $\begin{array}{l}\text { Try to coat the inside of ampoule with graphitic layer to prevent } \mathrm{Cd} \\
\text { attack on } \mathrm{SiO}_{2}\end{array}$ \\
\hline$\# 05$ & $\mathrm{CdGeAs}_{2}$ & Redo \#4 and try air quenching for an amorphous sample \\
\hline$\# 06$ & $\mathrm{CdGeAs}_{2}$ & Retry \#5 \\
\hline$\# 07$ & $\mathrm{CdGeAs}_{2}$ & Retry \#5 \\
\hline$\# 08$ & $\mathrm{CdGeAs}_{2}$ & Retry \#5 \\
\hline$\# 09$ & $\mathrm{CdGeAs}_{2}$ & Retry \#5 but try water quenching this time \\
\hline$\# 10$ & $\mathrm{CdGeAs}_{2}$ & Water quenching $\mathrm{CdGeAs}_{2}$ sample \\
\hline$\# 11$ & $\mathrm{CdGeAs}_{2}$ & $\begin{array}{l}\text { Try acid-etched ampoule w/o graphite, slow cool horiz. to prevent } \\
\text { cracking due to thermal expansion issues }\end{array}$ \\
\hline$\# 12$ & $\mathrm{CdGeAs}_{2}$ & Retry \#11 w/o acid etching ampoule \\
\hline$\# 13$ & $\mathrm{CdGeAs}_{2}$ & $\begin{array}{l}\text { Try acid-etched ampoule with graphite, slow cool horiz. to prevent } \\
\text { cracking due to thermal-expansion issues }\end{array}$ \\
\hline$\# 14$ & $\mathrm{CdGeAs}_{2}$ & $\begin{array}{l}\text { Try acid-etched ampoule with graphite, slow cool horiz. }\left(5^{\circ}\right) \text { to prevent } \\
\text { cracking due to thermal-expansion issues }\end{array}$ \\
\hline$\# 15$ & $\mathrm{CdGeAs}_{2}$ & $\begin{array}{l}\text { Try acid-etched ampoule with graphite, slow cool horiz. }\left(5^{\circ}\right) \text { to prevent } \\
\text { cracking due to thermal-expansion issues }\end{array}$ \\
\hline$\# 16$ & $\begin{array}{l}75 \mathrm{~m} \% \\
\mathrm{CdGe}_{0.6} \mathrm{As}_{2} \\
25 \mathrm{~m} \% \\
(\mathrm{GeSe})_{57}\left(\mathrm{GeSe}_{2}\right)_{43}\end{array}$ & $\begin{array}{l}\text { Use Se-Ge eutectic to help form amorphous material (using } 75 \text { mass } \% \\
\mathrm{CdGeAs}_{2} \text { and } 25 \text { mass } \% \text { of } \mathrm{GeSe} / \mathrm{GeSe}_{2} \text { ) }\end{array}$ \\
\hline$\# 17$ & $\mathrm{CdGe}_{0.60} \mathrm{As}_{2}$ & Lower Ge to $0.6 \mathrm{~mol}$ ratio as per Hong/Speyer paper data \\
\hline$\# 18$ & $\mathrm{CdGe}_{0.45} \mathrm{As}_{2}$ & Lower Ge to $0.45 \mathrm{~mol}$ ratio as per Hong/Speyer paper data \\
\hline \#19 & $\mathrm{CdGe}_{0.45} \mathrm{As}_{2}$ & Lower Ge to $0.45 \mathrm{~mol}$ ratio as per Hong/Speyer paper data \\
\hline$\# 20$ & $\mathrm{CdGe}_{0.45} \mathrm{As}_{2}$ & $\begin{array}{l}0.45 \text { mol ratio of Ge, CVD hexane coating (trying more uniform C- } \\
\text { coating) }\end{array}$ \\
\hline \#21 & $\mathrm{CdGe}_{0.45} \mathrm{As}_{2}$ & $\begin{array}{l}\text { Recreate \#3 (DC), with } 0.45 \text { mol ratio of Ge, with } \mathrm{Si}-\mathrm{C} \text { as thermal } \\
\text { conductor between inner and outer FQ tube }\end{array}$ \\
\hline \#22 & $\mathrm{CdGe}_{0.45} \mathrm{As}_{2}$ & $\begin{array}{l}\text { Try end cap: using a } 8 \times 10-\mathrm{mm} \text { FQ inner tube and a } 10.5 \times 12.75-\mathrm{mm} \text { FQ } \\
\text { outer tube both carbon coated on interior (all edges of sample were } \\
\text { covered with carbon) }\end{array}$ \\
\hline \#23 & $\mathrm{CdGe}_{0.45} \mathrm{As}_{2}$ & $\begin{array}{l}\text { Recreate \#21 using } \mathrm{Cu} \text { powder as the thermal conductor between the } \\
\text { inner and outer tubes - entire assembly was } \sim 6 \mathrm{in} \text {. long }\end{array}$ \\
\hline$\# 24$ & $\mathrm{CdGe}_{0.45} \mathrm{As}_{2}$ & $\begin{array}{l}\text { Try out carbon-coated ampoule that is shorter in length than previous } \\
\text { ampoules to make sure that its entirety is in the hot zone }\end{array}$ \\
\hline$\# 25$ & $\mathrm{CdGe}_{0.55} \mathrm{As}_{2}$ & $\begin{array}{l}\text { Try smaller thickness fused quartz tube ( } 1 \mathrm{~mm} \text { vs. the } 1.125 \mathrm{~mm}) \\
\text { graphitized with acetone; } 0.55 \text { mol ratio Ge; double containment with } \\
\text { silver powder as thermal conductor between tubes }\end{array}$ \\
\hline \#26 & $\mathrm{CdGe}_{0.65} \mathrm{As}_{2}$ & $\begin{array}{l}\text { Try smaller thickness fused quartz tube }(1 \mathrm{~mm}) \text { as well as a different } \\
\text { stoichiometry }(0.65 \mathrm{~mol} \text { ratio } \mathrm{Ge}) \text { in a single containment ampoule }\end{array}$ \\
\hline$\# 27$ & $\mathrm{CdGe}_{0.65} \mathrm{As}_{2}$ & $\begin{array}{l}\text { Try a double containment ampoule using the } 10 \times 12 \mathrm{FQ} \text { and silver } \\
\text { powder as conductor between tubes using } 0.65 \mathrm{~mol} \text { ratio of } \mathrm{Ge}\end{array}$ \\
\hline$\# 28$ & $\mathrm{CdGe}_{0.85} \mathrm{As}_{2}$ & $\begin{array}{l}\text { Try a different composition }(\mathrm{Ge}=0.85) \text {, double containment, copper } \\
\text { powder as thermal conductor, shorter ampoule }\end{array}$ \\
\hline$\# 29$ & $\mathrm{CdGe}_{0.65} \mathrm{As}_{2}$ & $\begin{array}{l}\text { Redo \#27 using copper powder as thermal conductor to match details of } \\
\# 23 / \# 28 \text { to create a sample matrix with varying compositions }\end{array}$ \\
\hline$\# 30$ & $\mathrm{CdGeAs}_{2}$ & $\begin{array}{l}\text { Try another } \mathrm{Ge}=1.00 \text { ampoule using double containment, copper powder } \\
\text { as thermal conductor, shorter ampoule, etc. as in } \# 23 / \# 28 / \# 29\end{array}$ \\
\hline
\end{tabular}




\subsection{Characterization of Amorphous $\mathrm{CdGe}_{(0.45-1.00)} \mathrm{As}_{2}$}

The next step of the project is to characterize the ingots that have been synthesized. The data gained from these experiments provide important understanding of the synthesis process, to improve it, as well as how to modify material properties. The specific topics addressed are sectioning and polishing protocols and results from optical microscopy, X-ray diffraction (XRD), scanning electron microscopy (SEM), optical spectroscopy, particle-induced X-ray emission (PIXE) and Rutherford backscattering (RBS), and electrical testing.

\subsection{Sectioning and Polishing Protocols}

Excluding the first few samples, all of the samples were mounted in an epoxy resin before cutting to minimize sample damage during the sectioning and polishing steps. Halfway through FY06, we switched from using epoxy to using an acrylic resin to cast and encapsulate the specimens. The advantage of this approach was that the castable acrylic resin is soluble in acetone and allows the sample to be extracted from the casting without damaging it. This is particularly useful because the encapsulant can interfere with some analyses.

After casting in resin, the samples were sectioned using a slow-speed diamond saw. This material is relatively soft and brittle; thus, the resin casting helps minimize sample damage during the sectioning step. Nonetheless, it was common for specimens to crack, chip, or otherwise become damaged during sectioning. The ultimate tool to use for this purpose is a wire saw with optimized settings and parameters. These tools are commonly applied in the semiconductor industry because of the minimal amount of damage they create in specimens. Fortunately, one of the other NA-22 projects at PNNL has ordered such a saw, and we will be able to use it once it becomes available in mid-FY07.

Sections were cut from the ingots in various thicknesses, but for most characterization purposes, a thickness of 3 to $5 \mathrm{~mm}$ was ideal. After sectioning, the specimens would then be polished. Most of this work was done at PNNL in a metallography laboratory specifically dedicated to sample preparation. The appropriated environmental, safety, and health precautions and procedures for handling our samples and other NA-22 toxic specimens were developed and in place by mid-FY06. The results obtained were excellent. Hand polishing in a dedicated fume hood was used for those specimens that did not require a superior surface finish.

\subsection{Optical Microscopy}

Optical microscopy provides an important visual representation of the morphology of the microstructure. The information obtained provides informative feedback on the effectiveness of the processing method used to create it. Specimens were analyzed using reflected, cross-polarized light. This technique provides vivid images of crystalline features as the birefringence of the crystals at various orientations retards the reflected light in different amounts, thus producing different colors. Figure 3.1 shows a collage of reflected cross-polarized light from optical micrographs of specimens with varying concentrations of $\mathrm{Ge}$ and processed under different conditions. The specimen in Figure 3.1A (ASGRAD-05) was air cooled, and the color variations are due to different crystals at different orientations and illustrate the polycrystalline microstructure. Figure 3.1B (ASGRAD-10) is a specimen with the same composition as in A, but it was water quenched instead of air cooled. The center is multi- 
colored, which is an indication of a polycrystalline microstructure. However, the rim around the outer perimeter looks distinctly different. It was most likely amorphous and not birefringent like the crystals in the center, and thus had a uniform appearance. The micrographs in C to E (ASGRAD-23, 35, and 28, respectively) all have a uniform appearance, which is optical proof of their amorphous microstructure. The specimen in Figure 3.1F (ASGRAD-31) had the same composition of those in A and B, but was made using a double ampoule. The new process produced a much-improved microstructure with an amorphous matrix, but close examination shows that different types of crystals were still present within that amorphous matrix. The implementation of the gallium quench process mentioned above should allow us to synthesize amorphous, crack-free specimens of this composition.
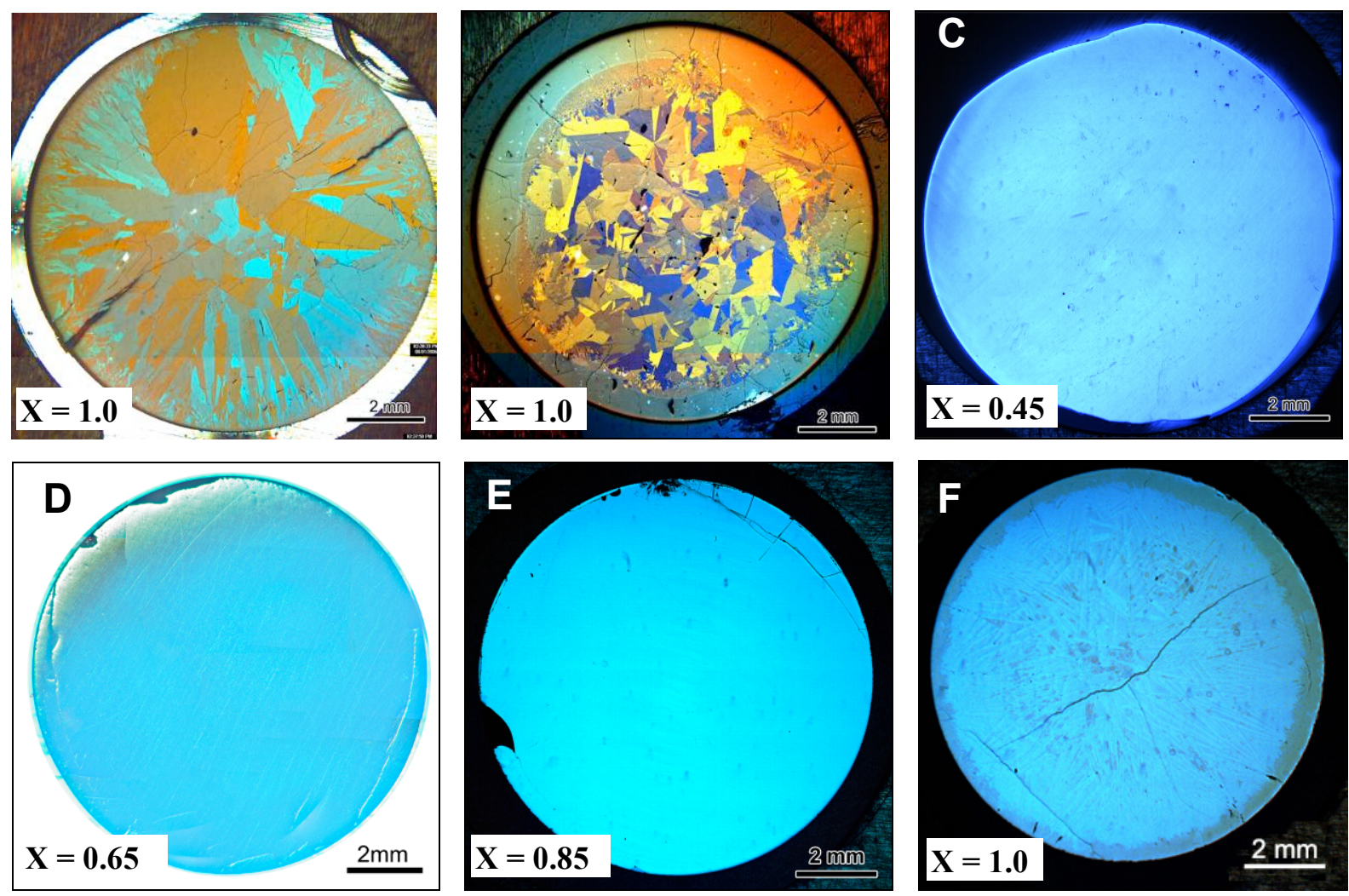

Figure 3.1. Reflected, cross-polarized optical micrographs of six cross-sectioned specimens of $\mathrm{CdGe}_{\mathrm{X}} \mathrm{As}_{2}$ processed using different conditions.

\subsection{XRD Results}

While optical microscopy provides spatial information about the microstructure, XRD provides definitive information about the atomic structure of the sample (crystalline vs. amorphous) and potentially, the exact identity of any crystalline phases that might be present. X-ray diffraction measurements were performed with a Scintag PAD V diffractometer using $\mathrm{Cu} K \alpha$ radiation $(\lambda=1.5406 \AA, 45 \mathrm{kV}$, and $40 \mathrm{~mA})$ and equipped with a Peltier-cooled $\mathrm{Si}(\mathrm{Li})$ solid-state detector. The experiments were done using $\theta$ to $2 \theta$ geometry in a step-scan approach from $10^{\circ}$ to $60^{\circ} 2 \theta$ with a step size of $0.04^{\circ} 2 \theta$ and a dwell time of 10 seconds per step. Each sample was mounted on a holder that rotated in the $x-y$ plane to minimize preferred crystal orientation effects. Since most of the samples were not in a powder form (all except for one), preferred orientation artifacts were observed in the results. The preferred crystal orientation causes the relative peak heights to be different than for a sample with randomly oriented crystals. Figure 3.2 
summarizes the XRD results for different $\mathrm{CdGe}_{x} \mathrm{As}_{2}$ materials varying in composition. The scans seen in Figure 3.2 were performed with the sample mounted in an acrylic resin, and the large amorphous background hump from $\sim 13^{\circ}$ to $23^{\circ}$ was an artifact from the resin. Subsequent analyses were done by removing the specimens from the resin before XRD analysis.

One of the more interesting results was the discovery of a new, unidentified phase in the ASGRAD30 specimen $\left(\mathrm{CdGe}_{X} \mathrm{As}_{2}, \mathrm{X}=1.0\right)$, the top spectra in Figure 3.2. Hong et al. published a paper that analyzed the crystallization pathways of various amorphous Cd-Ge-As glasses (Hong et al. 1990). They reported the thermal analysis data and the corresponding XRD data at key temperatures based on the points of thermodynamic transitions as indicated from the DSC results. The XRD data collected for ASGRAD-30 does not match with any of their

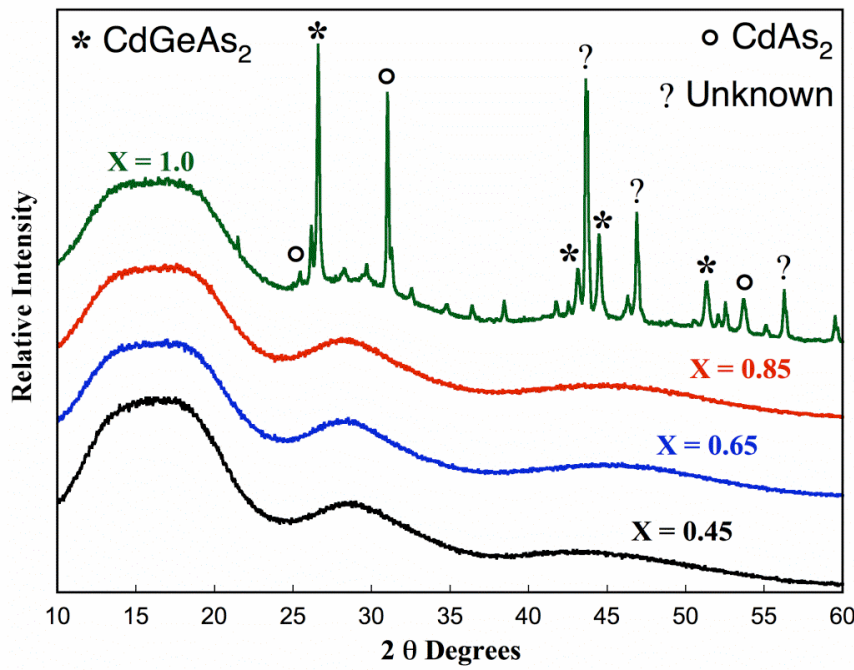

Figure 3.2. $\mathrm{XRD}$ results for $\mathrm{CdGe}_{\mathrm{x}} \mathrm{As}_{2}$ compositional variation. results. Consequently, we are investigating this phase in greater detail to determine if indeed this is a new crystalline phase in the As-Cd-Ge system. This will be done on a not-to-interfere basis with the main emphasis of the project.

\subsection{SEM Results}

Selected specimens were analyzed with an SEM to evaluate their homogeneity and to look for contaminants. Back scattered electron (BSE) imaging was used, which produces an image where the contrast is sensitive to differences in average atomic number-heavier elements appear brighter. Energy dispersive spectroscopy (EDS) was done to confirm elemental composition and to examine for spatial distribution of elements. Figure 3.3 shows an example micrograph of a BSE image and the accompanying EDS dot map from near the edge of ASGRAD-10. An optical micrograph of this same specimen was shown in Figure 3.1B. The BSE image in A shows that the rim area, which is brighter, has a higher average atomic number than the interior. The optical micrograph shows that the rim was amorphous (no change in color upon rotation while being observed with reflected, cross-polarized light) and that the interior was crystalline. Compositionally, there is no observable difference in composition between the rim and the interior - the dot maps show no discernable difference in color intensity between the rim and the interior. The conclusion is that the amorphous phase of this material must be denser than the crystalline phase, hence the reason why it appears brighter in the BSE mode than the interior (BSE mode is sensitive enough to distinguish a 0.1 difference in average atomic number). This is consistent with information reported in the literature where it was stated that amorphous $\mathrm{CdGeAs}_{2}$ was $2 \%$ more dense than the crystalline phase (Hong et al. 1990). The explanation for this unusual variance is that the crystalline state has a more open structure than the amorphous state due to the arrangement of Ge in intestinal sites. 
One of the other important observations from the BSE and EDS dot map data were the inhomogeneities of the specimen. For example, the thin, bright, irregular line in the upper left quadrant of Figure 3.3A had a locally higher concentration of $\mathrm{Cd}$ and As, as shown in the dot maps in D to H. Additionally, some of the black irregular lines in Figure 3.3A are indicative of carbon-rich areas, as shown by the corresponding red lines in $\mathrm{B}$ and the composite images in $\mathrm{F}$ and $\mathrm{G}$. Two conclusions and process modifications were drawn from this. First, the melt needs to be homogenized better. The plan is to increase the rocking rate of the specimen during thermal processing to promote better mixing. The second conclusion was that since the ampoule had been carbon coated, some of the pyrolized carbon from the coating process must have flaked off the ampoule wall and contaminated the melt. This contamination could either provide nucleation sites for crystallization or serve as point defects in the material. The options were to either perfect the carbon coating process or abandon it. Based on the success in processing Cd-Ge-As ingots in un-coated ampoules, our intention is to eliminate this step from the process.

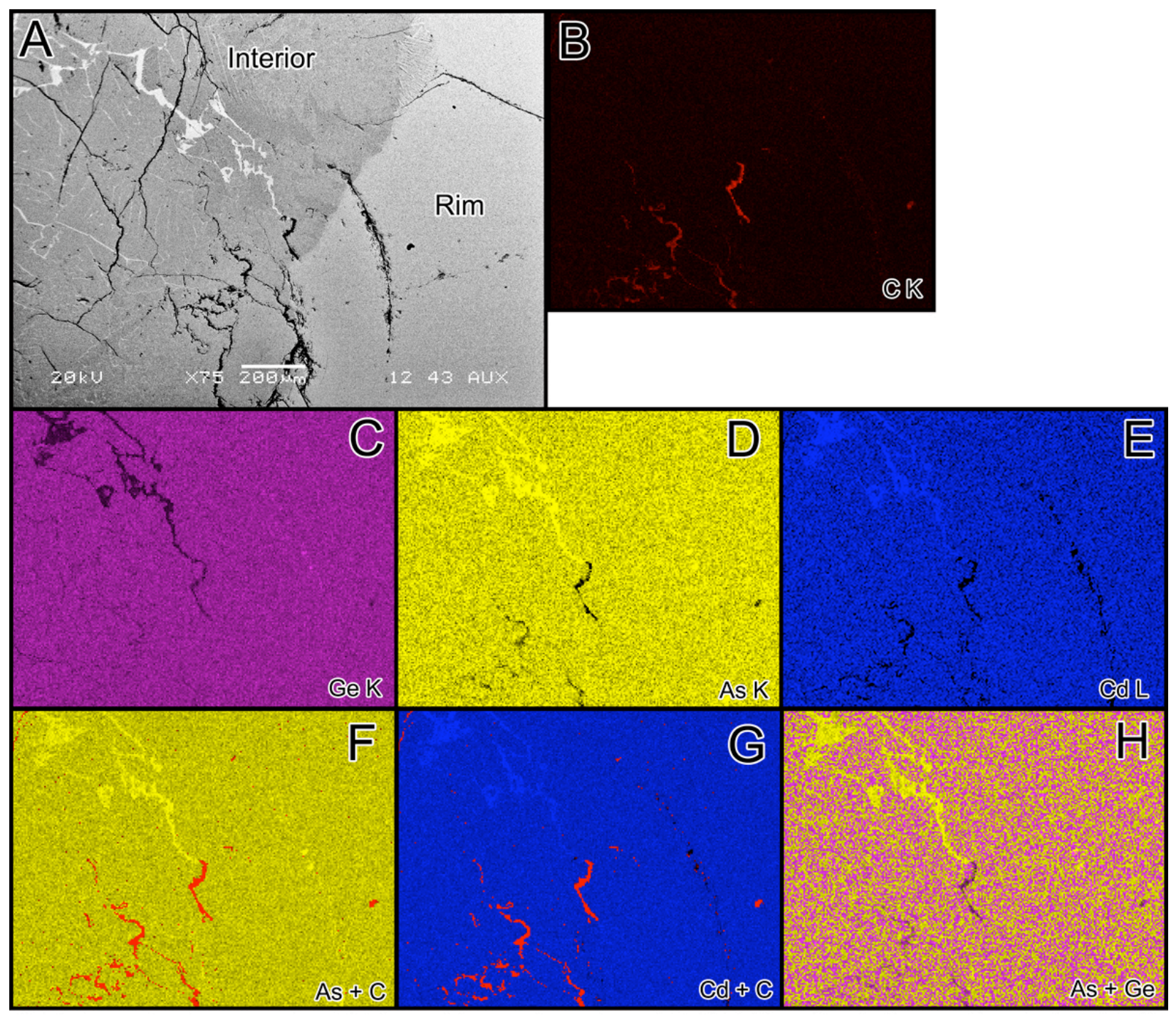

Figure 3.3. SEM BSE micrograph (A) and accompanying EDS elemental dot maps (B to $\mathrm{H}$ ) for ASGRAD-10, a water-quenched specimen with a composition of $\mathrm{CdGe}_{1.0} \mathrm{As}_{2}$. The contrast in (A) is due to differences in average atomic number. The intensity of the colors in B to $\mathrm{E}$ is qualitatively proportional to concentration; the images in $\mathrm{F}$ to $\mathrm{H}$ are composite images. 


\subsection{Optical Spectroscopy}

Characterization with optical spectroscopy provides information about possible contamination by oxygen, hydroxide, and hydrocarbon species. These contaminants can be present in the as-received elements, as well as introduced through the synthesis process. The presence of characteristic vibrational peaks in the FTIR spectrum is a good test for these contaminants. Absorption spectroscopy using an ultraviolet visible near infrared (UV-Vis-NIR) spectrometer is particularly

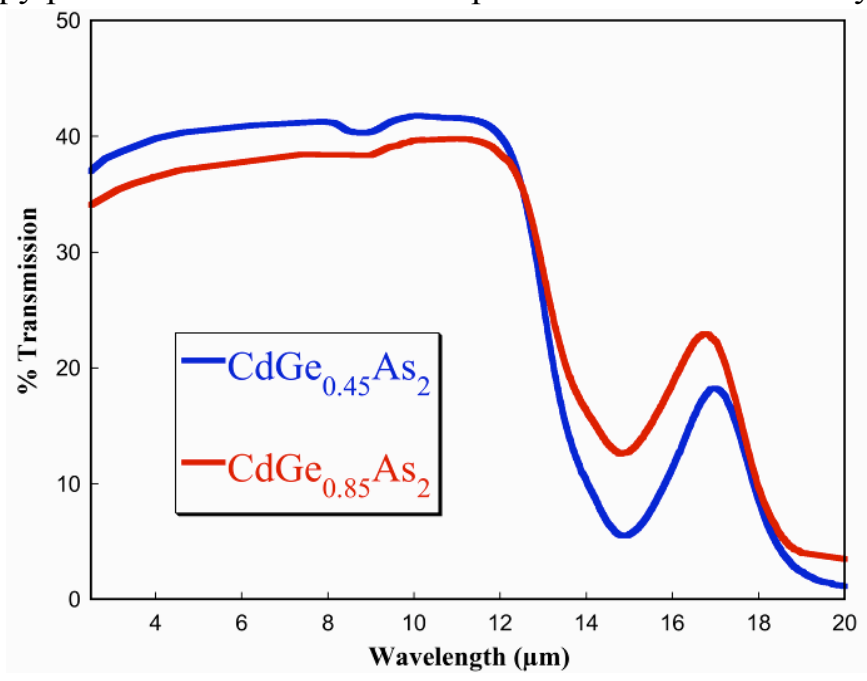

Figure 3.4. FTIR spectroscopy performed on two different compositions. useful for characterizing the electrical conduction processes at the band edge as well as measuring the value of the band gap. Figure 3.4 shows transmission spectra taken with a Fourier transform infrared (FTIR) spectrometer for two different $\mathrm{Cd}-\mathrm{Ge}-\mathrm{As}$ glasses. The relatively smooth curve between 2 to $10 \mu \mathrm{m}$ was free from the characteristic vibrations due to typical contaminants such as oxygen, hydroxides, and hydrocarbon, which would have been visible at ppm concentration levels. These data confirm that the glove-box, UHV synthesis process we are using is effective in minimizing contamination. Some preliminary absorption spectra have been collected at PNNL, however the majority of this work will be done in FY07 by University of Illinois at Urbana-Champaign (UIUC) as samples become available.

\subsection{PIXE and RBS}

Ion beam analysis (IBA) techniques are based on ion-solid interaction, as shown in

Figure 3.5. When a moving charged particle of $\mathrm{MeV}$ energy range strikes a material, it interacts with the electrons and nuclei of the material's atoms, slows down, and possibly deviates from its initial trajectory. Different atomic and nuclear processes can lead to the emission of particles or radiation whose energy is characteristic of the elements that constitute the sample material. The numerous IBA techniques, such as PIXE spectrometry and RBS spectrometry, have developed into a mature field of applied material science.

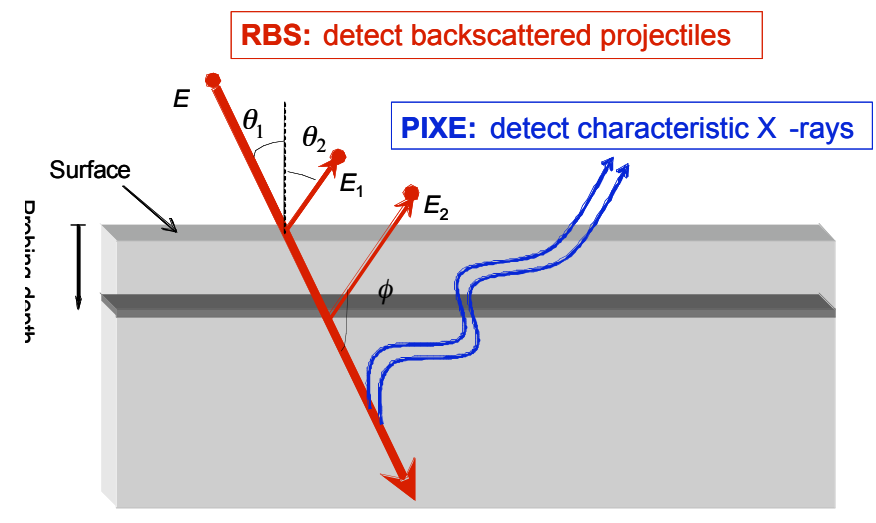

Figure 3.5. Schematic drawing of ion-solid interaction. 
PIXE is a powerful and relatively simple analytical technique that can be used to identify and quantify trace elements typically ranging from $\mathrm{Al}$ to $\mathrm{U}$. As a charged particle moves through a material, it loses energy, primarily by exciting electrons in the atoms that it passes by. Electrons from the inner shells of the atom (predominantly the $\mathrm{K}$ and L shells) are given enough energy to cause them to be ejected. Electrons from outer shells fill these vacancies and give off excess energy in the form of X-rays. The energies of these X-rays are characteristic of the element within the sample and therefore can be used to identify elemental composition.

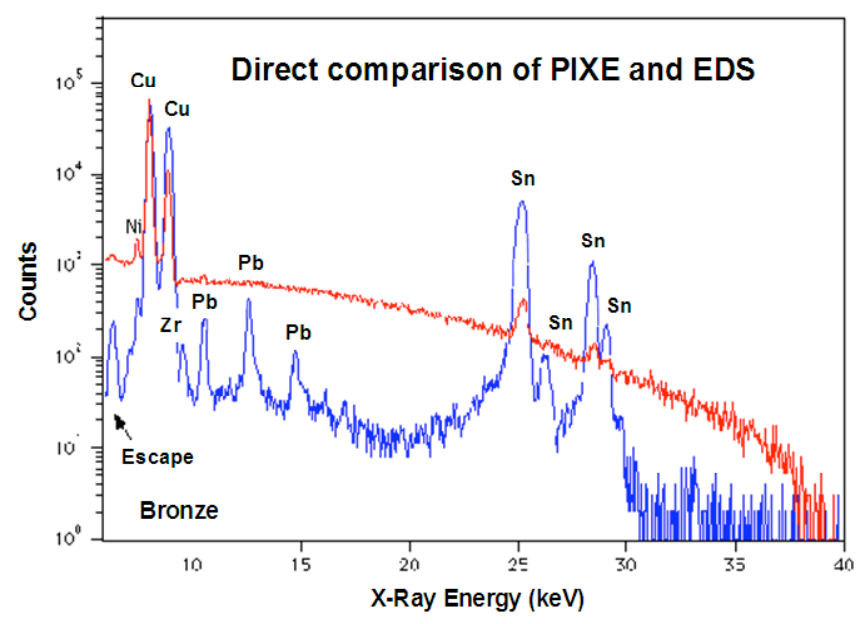

Figure 3.6. Comparison of PIXE and EDX. By measuring intensities of characteristic X-ray lines, one can determine concentrations of the elements in the sample. A high probability of X-ray emission makes PIXE a very sensitive analytical technique. For most elements, the detection limit is down to approximately $1 \mathrm{ppm}$ (part-per-million). A comparision from a random sample (not from ASGRAD) as shown in Figure 3.6, illustrates the higher trace element sensitivity and better peak-to-noise ratios of PIXE as compared to electron-based X-ray analytical techniques such as EDS. RBS differs from PIXE. Instead of characteristic X-rays, those incident ions are scattered from target atom nuclei and are subsequently detected, yielding information on the mass and depth of the target atoms.

PIXE measurements were carried out with a $2.5-\mathrm{MeV} \mathrm{H}^{+}$beam, and the $\mathrm{X}$-rays emitted during the deexcitation process within the atoms were analyzed using a Li-drifted Si detector positioned at an exit angle of $39^{\circ}$. First, the PIXE spectrum from the National Institute for Standards and Technology (NIST) standard was obtained. The GUPIX computer code, developed at the University of Guelph, Canada, was used to fit the experimental data. In this fitting, the background due to bremsstrahlung was removed, and peak areas under each peak were converted into concentrations using experimental parameters such as energy, incident and exit angles, charge, solid angle of the detector, absorber thickness, and detector response functions. Our experimental parameters were then calibrated against the known concentrations of the standard. After these calibrations, we performed PIXE measurements on actual samples. RBS measurements were performed with $2.0-\mathrm{MeV} \mathrm{He}^{+}$ions at a scattering angle of $165^{\circ}$. The SIMNRA simulations code was used to fit the RBS data. The PIXE and RBS spectra of ASGRAD-23 $\left(\mathrm{CdGe}_{0.45} \mathrm{As}_{2}\right)$ and ASGRAD-30 $\left(\mathrm{CdGe}_{1.0} \mathrm{As}_{2}\right)$ are shown in Figure 3.7 and Figure 3.8, respectively. These illustrate typical experimental resolution and counting statistics. For ASGRAD samples, PIXE and RBS techniques are used in a complementary manner where PIXE determines the relative ratio of As:Ge, as shown in Figure 3.7, and RBS determines the absolute concentration of Cd, as shown in Figure 3.8. Furthermore, the superior resolution of PIXE enables the possible detection of trace elements of Fe and $\mathrm{Ni}$, as indicated by the clear peaks at lower energies in Figure 3.7. Table 3.1 shows combined, tabulated results of PIXE and RBS analyses for several different samples. 

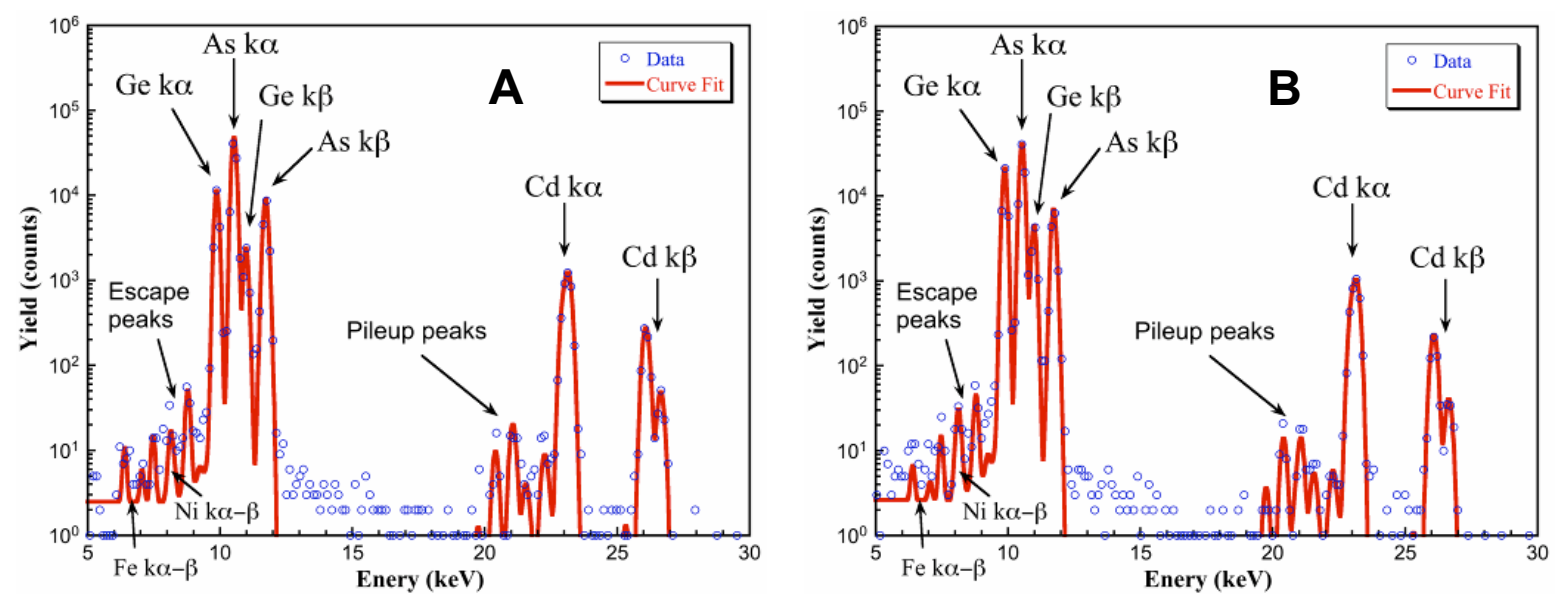

Figure 3.7. PIXE Results for ASGRAD-23 (amorphous $\mathrm{CdGe}_{0.45} \mathrm{As}_{2}$ ), (A), and ASGRAD-30 (polycrystalline $\mathrm{CdGe}_{0.45} \mathrm{As}_{2}$ ), (B).
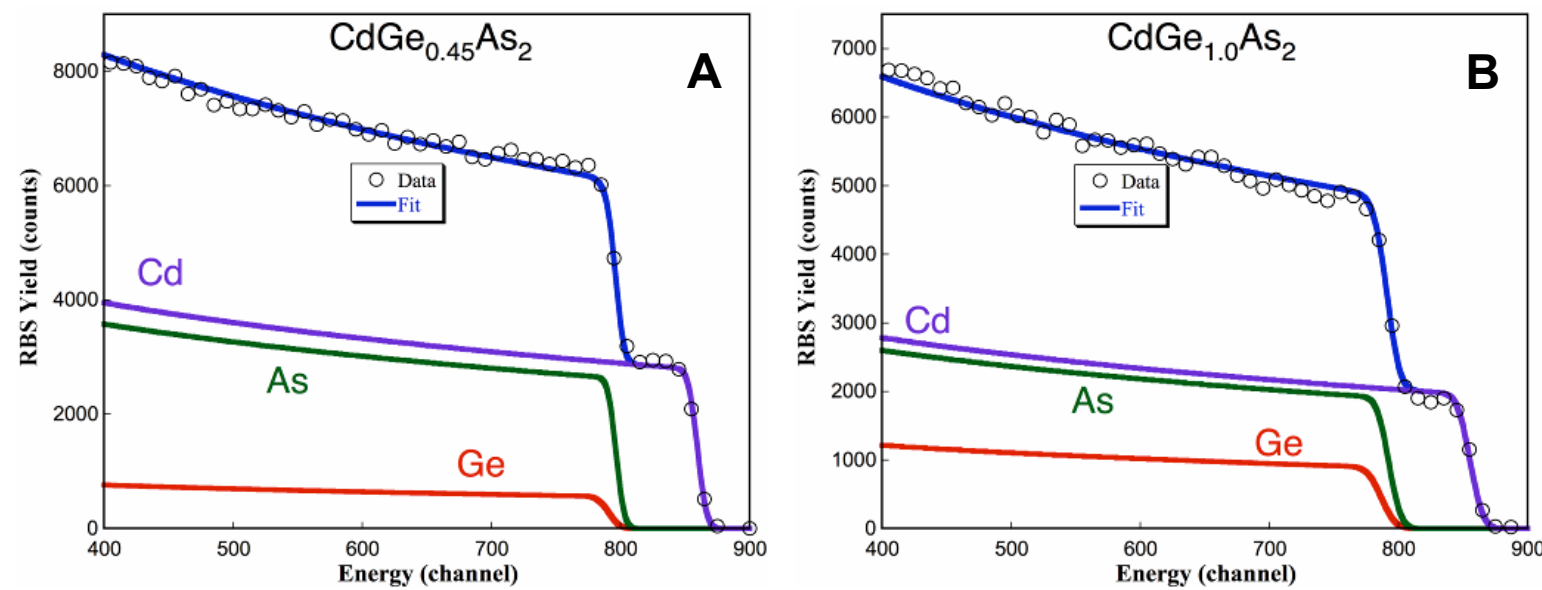

Figure 3.8. RBS Results for ASGRAD-23 (amorphous $\mathrm{CdGe}_{0.45} \mathrm{As}_{2}$ ), (A), and ASGRAD-30 (polycrystalline $\mathrm{CdGe}_{0.45} \mathrm{As}_{2}$ ), (B).

Table 3.1 summarizes the composition of the samples:

Table 3.1. Summary of compositional analysis from IBA experiments

\begin{tabular}{|c|c|c|c|c|c|c||}
\hline ID & Description & Cd (\%) & Ge (\%) & As (\%) & Fe (ppm) & Ni (ppm) \\
\hline ASGRAD-21 & $\mathrm{Cd}_{1.1} \mathrm{Ge}_{0.5} \mathrm{As}_{2}$ & 0.300 & 0.140 & 0.560 & 278 & 161 \\
\hline ASGRAD-23 & $\mathrm{Cd}_{1.0} \mathrm{Ge}_{0.45} \mathrm{As}_{2}$ & 0.294 & 0.131 & 0.575 & 376 & 167 \\
\hline & & & & & & \\
\hline ASGRAD-27 & $\mathrm{Cd}_{1.0} \mathrm{Ge}_{0.65} \mathrm{As}_{2}$ & 0.282 & 0.177 & 0.541 & 414 & 146 \\
\hline ASGRAD-29 & $\mathrm{Cd}_{0.9} \mathrm{Ge}_{0.65} \mathrm{As}_{2}$ & 0.253 & 0.184 & 0.563 & 381 & 179 \\
\hline & & & & & & \\
\hline ASGRAD-28 & $\mathrm{CdGe}_{0.85} \mathrm{As}_{2}$ & 0.259 & 0.221 & 0.520 & 322 & 186 \\
\hline & & & & & & 128 \\
\hline ASGRAD-30 & $\mathrm{CdGeAs}_{2}$ & 0.249 & 0.250 & 0.502 & 268 & 128 \\
\hline
\end{tabular}


The two most significant conclusions from these experimental results were as follows: 1) the synthesis process was able to achieve the desired, as batched, stoichiometry - there were no side reactions or material losses, and there were no compositional variations radially across the sample (Table 3.1), and 2 ) the synthesis process produced very high-purity specimens. There was some indication of contamination by transition metal elements such as Fe and Ni. It is known that these elements have deleterious effects on the electrical resistivity of Cd-Ge-As glass. Consequently, further characterization is planned to verify the source of these contaminants (e.g. from raw chemicals or the synthesis process) and determine the means to eliminate them.

\subsection{Electrical Testing Results}

These materials are being developed as the active medium for semiconductor-based gamma radiation detection. The physics of this detection process depend on both the generation of free electrons as gamma rays interact with the medium and the efficient collection of these charge carriers. As such, the electrical properties of the material greatly influence its radiation-detection capabilities. In one method of detection, electrical contacts are applied to the active semiconducting detecting material, and a large voltage is applied to it. This creates a large electric field that will accelerate the gamma-produced, free electrons to travel through the material to the electrical contacts, and create a pulse. Since the current produced from a single gamma photon is very small (nA range), the active detecting material needs to have a very high resistivity (e.g., $10^{9}$ to $10^{11} \mathrm{Ohm}-\mathrm{cm}$ ) to minimize leakage current (electrical noise). Thus, resistivity is a key electrical property for making an effective gamma radiation detector.

One way to characterize the resistivity of a material is to measure the current produced (I) as a function of the voltage (V) applied. These are called IV curves. There are facilities at PNNL dedicated to the electrical characterization of semiconductor materials used in radiation detection. Several specific pieces of equipment have been designed to permit automated data collection of IV curves from samples with and without exposing them to sealed sources. An environmental testing chamber that can reduce temperatures down to $-50^{\circ} \mathrm{C}$ is also available.

Preliminary measurements of IV curves were made at PNNL in the third and fourth quarters in FY06. However, the system (amplifier detection circuitry, etc.) was designed and optimized for testing other materials, such as $\mathrm{CdZnTe}$, and not the amorphous semiconductors being synthesized for this project. Thus, the data obtained were dominated by artifacts and were not representative of the actual material properties. This problem was not identified until the first quarter of FY07 when similar data from UIUC started coming in. Comparisons were made between the two data sets, and the problem became apparent as the discrepancies were being resolved. Consequently, we have initiated the design and construction of a suitable detection box and an ultra-low level noise, signal amplification circuit. This equipment should be in service for analyzing samples by the end of the second quarter in FY07. 


\subsection{Collaboration With the University of Illinois at Urbana-Champaign (UIUC)}

This project includes a portion for collaboration with the University of Illinois at Urbana-Champaign (UIUC). Our key collaborator at UIUC is Prof. Angus Rockett, who has extensive experience in semiconductor characterization research for photovoltaic applications. The intent of the collaboration is to couple areas of excellence in processing and characterization for the success of the project. Key property data collected and interpreted by UIUC include Hall Effect measurements, current-voltage (IV) characterization, and metallization strategies.

\subsection{Hall Effect Measurements}

Hall measurements are used to characterize the type and mobility of free charge carriers in a sample. Four electrical contacts are applied to the surface of a sample in the pattern of a square, and a voltage is applied to two contacts at opposite corners from each other. A magnetic field is applied to the sample perpendicular to the electrical field (vertical to the plane of the sample). As charge carriers move due to the applied electrical field, they are deflected perpendicular to their path of travel because of the magnetic field. The charge build up is monitored on the two contacts that do not have an external voltage applied to them. The polarity of the charge indicates the nature of the majority charge carriers (hole vs. electron), and the value of the charge build up is a measure of their mobility. In addition to mobility measurements, IV curves can also be generated. (Note: IV data are typically limited to voltages less than $10 \mathrm{~V}$ in Hall tests, whereas the IV set up used at PNNL is designed to measure IV curves up to $1000 \mathrm{~V}$, as would be typically used in radiation-detector applications.) Measurements are made as a function of applied voltage and as a function of temperature - samples are typically cooled to at least liquid nitrogen temperature.

Preliminary experiments were done using specimens sectioned from ASGRAD-5 and ASGRAD-10. These were polycrystalline ingots produced early in the development of the process before compositional and quenching modifications were made that enabled amorphous, crack-free ingots to be synthesized. The intent of the experiments was to develop familiarity with the testing protocol and with the material, and to generate some baseline data to compare with other future specimens. Figure 4.1 shows photographs of the testing apparatus. 

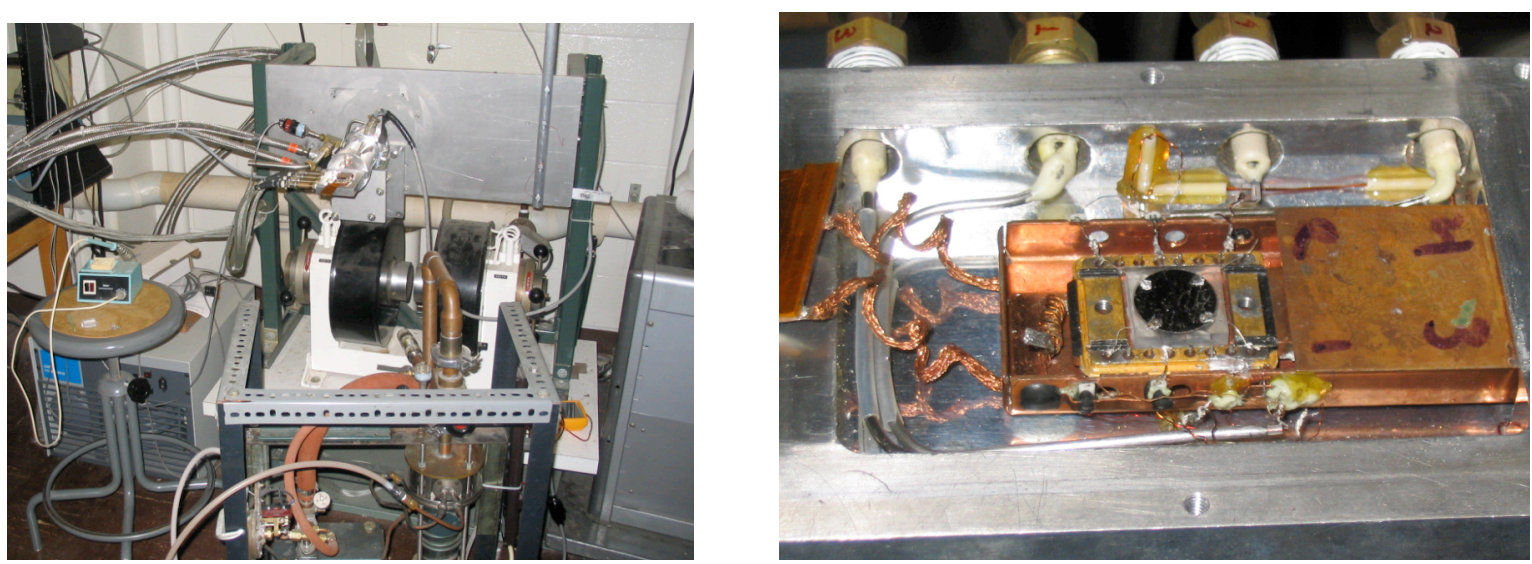

Figure 4.1. Photographs of the Hall mobility testing apparatus at UIUC. magnet (L) and ASGRAD sample in holder (R).

The capability to apply ohmic contacts to the material being tested is one of the critical details that needs to be addressed. This requires finding a metal with a work function such that the Fermi level of electrons in it is approximately equal to the Fermi level of electrons in the semiconductor. Other issues that need to be addressed are to find a suitable deposition method and to accommodate differences in thermal expansion coefficients so that the specimen can be temperature cycled. A number of different electrical contacts have been tried at UIUC, using various combination of $\mathrm{In}, \mathrm{Ti}$, and $\mathrm{Au}$. Problems have been observed with contact failures at low temperatures, so this development effort is still in progress.

\subsection{Current-Voltage Data}

Figure 4.2 shows room-temperature current-voltage measurements made at UIUC on a poly crystalline sample (ASGRAD-5) and an amorphous sample (ASGRAD-23). Close comparison of the data shows that there was a dramatic increase in resistance for the amorphous specimen-an increase of approximately 4 orders of magnitude. This is an important result because high resistivity is a key property for a semiconductor-based radiation detector, as discuss in Section 3.7. Figure 4.3 shows a plot of the resistivity as a function of temperature.
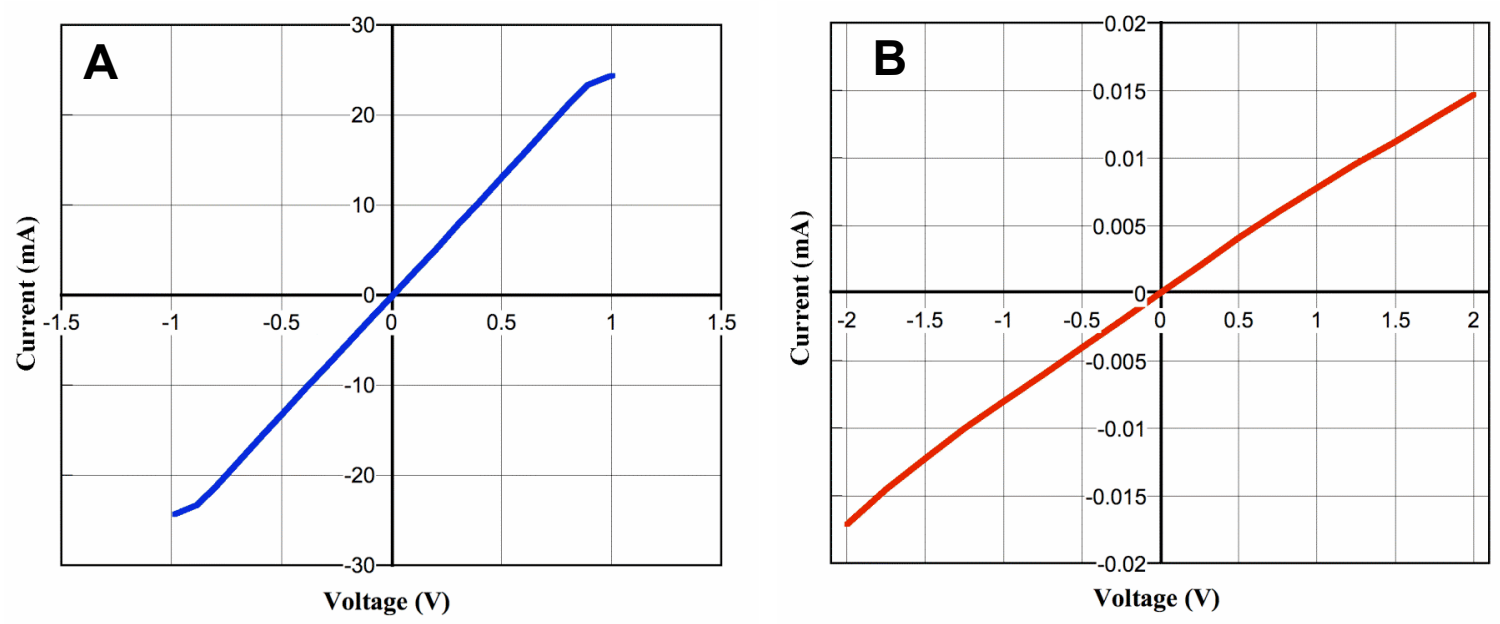

Figure 4.2. Current-Voltage curves measured by UIUC for a polycrystalline sample (A) ASGRAD-5 and an amorphous sample (B) ASGRAD-23. 


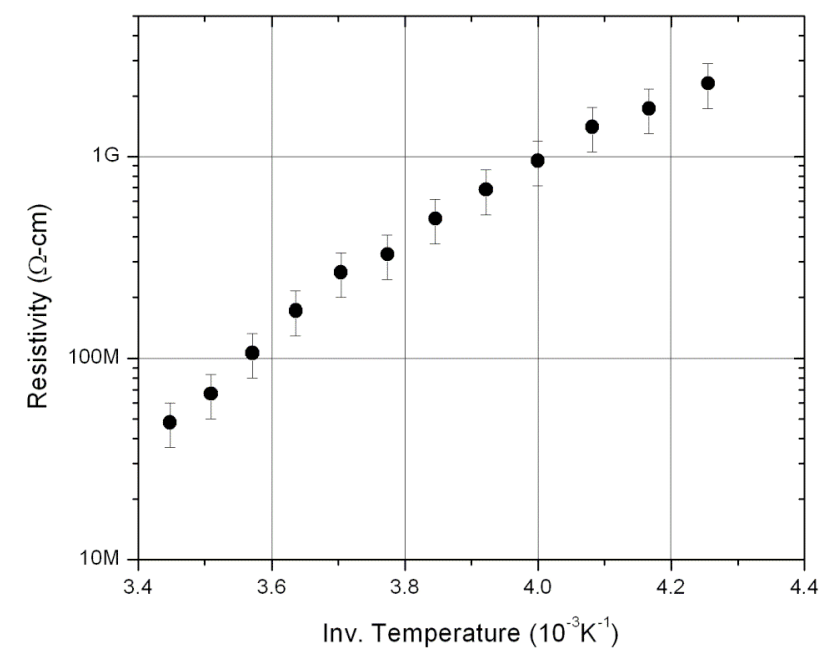

Figure 4.3. Resistivity as a function of temperature for amorphous specimen ASGRAD-23. 


\subsection{Strategy and Future Direction}

Based on the progress made in FY06 and the experience gained from synthesizing and characterizing ingots of Cd-Ge-As glass, the strategy and future direction of the project are discussed.

\subsection{Strategy}

The statement of work (SOW) for FY07 specifies expanding this research project to cover two additional materials: $\mathrm{AgGaTe}_{2}$ and $\mathrm{CuInSe} \mathrm{S}_{2}$. These are valuable materials with promising properties for radiationdetection applications. The initial intent of the proposal was to use $\mathrm{CdGeAs}_{2}$ as a known glass former to build a baseline of experience in amorphous semiconductor materials for gamma radiation detection and then branch out to other structurally similar and promising systems (e.g., higher $Z_{\text {ave }}$ ). Since the initial electrical and semiconducting characterization results on amorphous $\mathrm{Cd}-\mathrm{Ge}-\mathrm{As}$ glass have been promising, and since the full electrical and radiation response testing characterization for Cd-Ge-As glass have not been completed yet, it seems prudent to continue to concentrate on further developing this material before diversifying into different material systems. Thus, we would like to modify the SOW for FY07 to focus on the continued the development and testing of amorphous Cd-Ge-As glass. The focus will be to develop and refine the testing tools and protocols used to characterize the electrical and radiation response of amorphous $\mathrm{Cd}-\mathrm{Ge}$-As glass, and to demonstrate broad compositional control of electrical and radiation response properties.

\subsection{Future Direction}

The electrical and radiation response testing effort will leverage the existing capabilities developed for single crystal CdZnTe radiation detector materials. Advances and upgrades to the system are planned to accommodate the unique sample specific needs of Cd-Ge-As glass. A new testing fixture has been designed and is being built for this purpose. Compositional changes to the Cd-Ge-As glass are planned with the goal of demonstrating compositional control of radiation response properties. Four specific areas for optimization have been targeted: 1) increase resistivity, 2) minimize the density of defect states in the band gap, 3) develop doping/alloying strategies to create $\mathrm{p}$ - and n-type materials and build Schottky barrier contacts (metallization needs are included as a part of this), and 4) increase the band gap. We feel this change in the SOW is prudent in light of the level of effort required to synthesize and characterize new materials. We also believe that the project will benefit from the greater productivity and increased understanding gained by concentrating on the one material system. 


\subsection{Appendix: Pyrolytic Carbon Coatings}

Many of the initial attempts to form ingots of amorphous Cd-Ge-As resulted in small, hairline cracks in the wall of the ampoule and a loss of containment. This appeared to be caused by a chemical attack on the quartz by the melt components, primarily $\mathrm{Cd}$. The $\mathrm{Cd}$, in liquid form, apparently wetted the fused quartz and then, upon cooling, cracked the fused quartz because of mismatched thermal expansion between the $\mathrm{Cd}$ and fused quartz. There were reports in the literature referring to problems where certain components could attack open quartz surfaces during processing and possibly compromise the integrity of the ampoule (Sharma et al. 1989). Several of the papers in the literature focused on processing chalcopyrites and other non-oxide materials by coating the interior of the reaction vessel with carbon or graphite. This was accomplished by pyrolizing acetone in low-oxygen conditions with a torch (Hong et al. 1990; Sharma et al. 1989).

To eliminate the problem of the ampoules cracking (and provide a getter for trace oxygen in the ampoule), we investigated the possibility of applying graphite coatings to the interior of our ampoule walls. We used two different approaches. The simplest approach was to put approximately 10 $\mathrm{mL}$ of acetone in a cleaned ampoule and swirl the liquid around so that it coated the entire interior surface. The excess acetone was poured out, and the ampoule was inverted. A torch was then used to heat the outside wall of the ampoule and pyrolize the thin film of acetone so as to leave a thin coating of carbon on the walls of the tube. This was an easy process, but the biggest disadvantage was that it did not result in a reproducible, uniform, controlledthickness carbon coating. Thus, a more accurate, controllable process was sought.

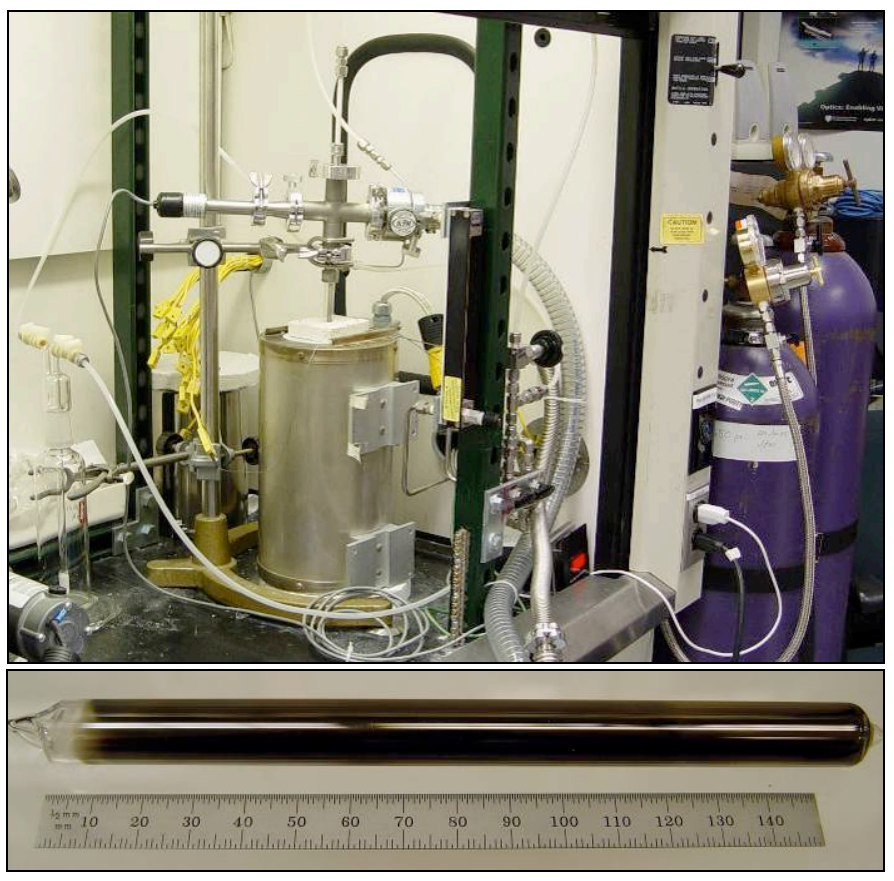

Figure 6.1. Top: CVD apparatus for applying graphite coating to quartz tubes; Bottom: evacuated and sealed quartz tube with graphite coating on interior.

A paper published by Harrison et al. (2006) described the details of a chemical vapor deposition (CVD) process they had optimized to create high-purity graphite coatings on the inside walls of quartz tubes using hexane or acetone as the graphite precursor and $\mathrm{Ar}$ and $\mathrm{N}_{2}$ as the carrier gases. A comparable apparatus was assembled in our laboratory, as shown in Figure 6.1.

To seal the graphite-coated ampoules, it was necessary to remove the graphite layer from the top portion of the tube. The oxygen-propane torch was used to burn off the graphite coating for this purpose. The ampoules were annealed after applying the graphite coating before filling it with the elements. A sealed, graphite-coated fused quartz ampoule is shown in Figure 6.1 


\subsection{References}

Harrison MJ, AP Graebner, WJ McNeil, and DS McGregor. 2006. "Carbon coating of fused silica ampoules." Journal of Crystal Growth 290(2):597.

Hong KS, Y Berta, and RF Speyer. 1990. "Glass-crystal transition in II-IV-V . $_{2}$ semiconducting compounds." Journal of the American Ceramic Society 73(5):1351.

Hruby A. 1972. "Evaluation of Glass-Forming Tendency by DTA." Czechoslovak Journal of Physics B22:1187-93.

Hruby A, and L Stourac. 1969. "Semiconducting glasses based on $\mathrm{CdAs}_{2}$." Materials Research Bulletin 4(10):745-756.

2007. CRC Handbook of Chemistry and Physics, Internet Version 2007, (87th Editiion). Taylor and Fancis, Boca Raton, FL.

Risbud SH. 1996. "Processing and properties of some II-IV-V ${ }_{2}$ amorphous and crystalline semiconductors." Applied Physics A: Materials Science \& Processing 62(6):519.

Roy UN, M Groza, Y Cui, A Burger, ZW Bell, and DA Carpenter. 2004. "Crystal growth, characterization and fabrication of $\mathrm{AgGaSe}_{2}$ crystals as a novel, material for room-temperature radiation detectors." In, Denver, CO, United States, International Society for Optical Engineering, Bellingham, WA 98227-0010, United States.

Rud V, Y Rud, I Poluushina, T Ushakova, and S Iida. 2000a. "Observation of Record Electron Hall Mobility in CdGeAs 2 Single Crystals." Jpn. J. Appl. Phys 39(Suppl. 39-1):266-267.

Rud VY, YV Rud, R Pandey, and MC Ohmer. 2000b. "Evidence of high electron mobility in $\mathrm{CdGeAs}_{2}$ single crystals." In, Boston, MA, USA, Mater. Res. Soc.

Sharma S, KS Hong, and RF Speyer. 1989. "Glass formation in chalcopyrite structured semiconducting compounds." Journal of Materials Science Letters 8(8):950. 